\title{
Structures of LIG1 engaging with mutagenic mismatches inserted by pol $\beta$ in base excision repair
}

Melike Caglayan ( $\nabla$ caglayanm@ufl.edu )

University of Florida https://orcid.org/0000-0003-1107-1042

\section{Qun Tang}

University of Florida

Robert McKenna

University of Florida

\section{Article}

Keywords:

Posted Date: January 14th, 2022

DOI: https://doi.org/10.21203/rs.3.rs-1150998/v1

License: (c) (1) This work is licensed under a Creative Commons Attribution 4.0 International License.

Read Full License

Version of Record: A version of this preprint was published at Nature Communications on July 5th, 2022. See the published version at https://doi.org/10.1038/s41467-022-31585-w. 
4 Department of Biochemistry and Molecular Biology, University of Florida, Gainesville, FL 532610, USA

$6{ }^{*}$ To whom correspondence should be addressed. Tel.: +1 352-294-8383; Email:

$7 \quad$ caglayanm@ufl.edu

\section{ABSTRACT}

9 DNA ligase I (LIG1) catalyzes final ligation step following DNA polymerase (pol) $\beta$ gap

10 filling and an incorrect nucleotide insertion by pol $\beta$ creates a nick repair intermediate

11 with mismatched end at the downstream steps of base excision repair (BER) pathway.

12 Yet, how LIG1 discriminates against the mutagenic 3'-mismatches at atomic resolution

13 remains undefined. Here, we determined X-ray structures of LIG1/nick DNA complexes

14 with G:T and A:C mismatches and uncovered the ligase strategies that favor or deter

15 ligation of base substitution errors. Our structures revealed that LIG1 active site can

16 accommodate $G: T$ mismatch in a similar conformation with $A: T$ base pairing, while it

17 stays in the LIG1-adenylate intermediate during initial step of ligation reaction in the

18 presence of $\mathrm{A}: \mathrm{C}$ mismatch at 3 '-strand. Moreover, we showed mutagenic ligation and

19 aberrant nick sealing of the nick DNA substrates with 3 '-preinserted dG:T and dA:C

20 mismatches, respectively. Finally, we demonstrated that AP-Endonuclease 1 (APE1), as

21 a compensatory proofreading enzyme, interacts and coordinates with LIG1 during

22 mismatch removal and DNA ligation. Our overall findings and ligase/nick DNA

23 structures provide the features of accurate versus mutagenic outcomes at the final BER

24 steps where a multi-protein complex including polß, LIG1, and APE1 can maintain 25 accurate repair. 
26 Keywords: Base excision repair, DNA polymerase $\beta$, DNA ligase I, AP-Endonuclease 1,

27 Mutagenic ligation, Genome stability

\section{INTRODUCTION}

29 DNA strand breaks occur as intermediates during all DNA transactions including DNA 30 replication, DNA repair, and genetic recombination (1). Human DNA ligases catalyze a 31 phosphodiester bond formation between 5'-phosphate (P) and 3'-hydroxyl $(\mathrm{OH})$ termini on ends of the broken DNA strand, and therefore contribute to overall genome stability (2-5). Using a high-energy cofactor ATP and $\mathrm{Mg}^{2+}$, DNA ligases catalyze the ligation reaction including three chemical and sequential steps: (i) nucleophilic attack on ATP by the ligase and formation of a covalent intermediate in which adenylate (AMP) is linked to an active site lysine (LIG-AMP),

(ii) the AMP is transferred to the 5'-end of the 5'-phosphate-terminated DNA strand to form DNA-AMP intermediate, and (iii) the ligase catalyzes attack by 3'-OH of the nick on DNAadenylate to join adjacent 3'-OH and 5'-P ends and liberate AMP (6-13).

The accuracy of the nick sealing reaction at the end of DNA repair relies on the formation of a Watson-Crick base pair between the 5'-P and 3'-OH ends that requires high fidelity DNA synthesis by DNA polymerase (14). Base excision repair (BER) is the predominant DNA repair mechanism of small single-base DNA lesions (15). The BER pathway involves the mechanism of substrate-product channeling that entails subsequent enzymatic steps and hand off of the repair intermediates between BER proteins so that the release and accumulation of toxic and mutagenic single-strand break intermediates are minimized in cells (16-20). This repair pathway coordination involves consecutive DNA synthesis and nick sealing steps during which DNA polymerase (pol) $\beta$ incorporates a single nucleotide into a gap and the resulting nicked insertion product is handed off to the ligation step where DNA ligase (ligase I and III $\alpha$ ) joins 3'-OH and 5'-P ends to complete the BER pathway $(14,21)$. Pol $\beta$, an error-prone polymerase without $3^{\prime}-5^{\prime}$ exonuclease proofreading activity, can incorporate mismatch nucleotides at a 
51 frequency of 1 in $\sim 5000$ during template-directed DNA synthesis (22). This pol $\beta$ mismatch

52 product could generate a problematic nick repair intermediate for subsequent ligation step in

53 the BER pathway $(14,21)$. In the presence of 3'-damaged or modified DNA ends, DNA ligases

54 can fail resulting in the formation of 5'-adenylated-DNA intermediates (i.e. 5'-AMP), also

55 referred to abortive ligation products (23-25).

56 In our previous studies, we demonstrated the importance of pol $\beta$ and DNA ligase I (LIG1)

57 coordination for the accurate channeling of repair intermediates to maintain BER efficiency at

58 the downstream steps of the repair pathway (23-36). For example, we reported that the

59 incorporation of oxidized nucleotide 7,8-dihydro-8'-oxo-dGTP (8-oxodGTP) by pol $\beta$

60 confounds LIG1, leading to the formation of abortive repair intermediates $(26,27)$. In our recent

61 studies, we demonstrated that the formation of pol $\beta$ correct nucleotide insertion product that

62 shows a stable closed ternary complex conformation enables the recognition and ligation of the

63 nicked insertion product and its efficient hand off to next ligation step in the BER pathway

64 (32). Furthermore, we showed that the repair fidelity is affected by the situations involving 5-

65 methylcytosine $(5 \mathrm{mC})$ and oxidative $5 \mathrm{mC}$ base modifications in template DNA and the

66 disease-associated mutations linked to LIG1-deficiency syndrome lead to enhanced ligation

67 failure after pol $\beta$ 8-oxodGTP insertion $(33,34)$. Recently, we demonstrated the mechanism by

68 which LIG1 fidelity mediates the faithful substrate-product channeling, specifically low-

69 fidelity LIG1 results in the mutagenic ligation of 8-oxodGMP inserted by pol $\beta$ (35). These

70 studies contribute to understanding of important molecular determinants that ensure accurate

71 BER pathway coordination or result in impaired hand off from pol $\beta$ to DNA ligase. However,

72 it still remains unclear that how DNA ligase dictates accurate versus mutagenic outcomes for

73 pol $\beta$-mediated base substitution errors during the final nick sealing step of BER pathway.

74 Pol $\beta$ has been reported to be mutated in $30 \%$ of a variety of human tumors such as lung, gastric,

75 colorectal, and prostate cancer $(37,38)$. Several of the cancer-associated pol $\beta$ variants possess 
76 aberrant repair function in vitro such as a reduced fidelity stemming from impaired

77 discrimination against incorrect nucleotide incorporation as reported for pol $\beta$ cancer-associated mutant K289M $(39,40)$. The expression of these variants in cells induces cellular transformation and genomic instability (41-46). The mismatch nucleotide insertions by DNA polymerases during repair and replication processes can cause base substitutions, additions and deletions in case of no proofreading, leading to genome instability and human diseases (47). For example, G:T mismatches are among the more prevalent mismatches found in nature, arising from the deamination of 5-methylcytosine to thymine $(48,49)$. Furthermore, it has been reported that Watson-Crick like G:T mismatch, if left unrepaired, could lead to transition or transversion point mutations and be a prominent source of base substitution errors in tumor suppressor genes in multiple forms of cancer (50-53). Nevertheless, the extent to which discrimination by LIG1 counteracts mutagenic pol $\beta$ mismatch insertion-promoted repair intermediates at atomic resolution remains unknown.

In the present study, we defined the molecular basis of human LIG1 mismatch discrimination mechanism by moderate-resolution structures of LIG1/nick DNA duplexes harboring A:C and G:T mismatches at 3'-end. Our structures revealed that LIG1 active site can accommodate G:T mismatch in a similar conformation with A:T base pairing where the ligase validates mutagenic G:T ligation during the adenyl transfer step of ligation reaction (DNA-AMP). However, the

94 ligase active site exhibits large distortion where the position of 3 '-OH end rotates $50^{\circ}$ from the

95 nick DNA with A:C mismatch during the first step of ligation reaction where the active site 96 lysine (K568) residue stays adenylated (LIG1-AMP) and 5'-PO 4 end shows a conformational 97 change. In our ligation assays in vitro, we showed efficient and defective nick sealing of G:T and A:C mismatches, respectively. Furthermore, we found that LIG1 can ligate the nicked 99 repair product following pol $\beta$ dGTP:T mismatch insertion and deters nick sealing after dATP:C 100 insertion. Finally, our results demonstrated that, APE1, as a complementary proofreading 
enzyme, can remove a mismatched base from 3'-end of the nick DNA substrates by its exonuclease activity. We also showed APE1/LIG1 protein-protein interaction and functional

103 coordination for mismatch removal coupled to DNA ligation. Overall results reveal the

104 strategies of LIG1 engaging with mismatched nick DNA that govern ligation of base

105 substitution errors inserted by pol $\beta$ and demonstrate the requirement of a multi-protein 106 assembly (pol $\beta$, LIG1, and APE1) to maintain the repair efficiency at the downstream steps of

107 the BER pathway.

\section{RESULTS}

109 LIG1 engaging with nick repair intermediates with mismatched DNA ends

110 In our previous study, we reported that the pol $\beta$ mismatch insertion governs the channeling of

111 resulting nicked repair product to LIG1 with the exception of Watson-Crick-like dGTP 112 insertion opposite $\mathrm{T}$ (32). In order to elucidate the ligase strategies that deter or favor the

113 ligation of repair intermediates that mimic polß mismatch nucleotide insertion products at 114 atomic resolution, we determined the structures of LIG1/nick DNA duplexes with G:T and A:C 115 mismatches and Watson-Crick A:T base-pair (Table 1).

116 Our structures demonstrated the molecular mechanism of LIG1 engaging with nick DNA 117 harboring mutagenic mismatch at 3'-strand (Figure 1 and Supplementary Figure 1). In the 118 structure of LIG1 bound to nick DNA duplexes containing A:T and G:T, we showed that the 119 ligase active site can accommodate G:T mismatch in a similar conformation with Watson-Crick 120 A:T base pairing (Figure 1A and 1B). The structure comparisons revealed no significant 121 differences, with superimposition $\mathrm{C} \alpha$ root mean square deviation of $0.609 \AA$. In both LIG1/nick 122 DNA structures, the 5'-termini is adenylated in the crystals and DNA-adenylate (DNA-AMP)

123 intermediate is observed. This refers to the second step of ligation reaction when AMP is 124 transferred to 5 '-PO $\mathrm{PO}_{4}$ of nick DNA and shows that LIG1/nick conformation with A:T and G:T 125 is poised for step 3 (nick sealing). 
126 In contrast, significant rearrangements at LIG1 active site were observed near the A:C

127 mismatch. The structure of LIG1/nick DNA duplex with A:C revealed that the ligase active

128 site exhibits LIG1-adenylate conformation where the active side lysine residue (K568) is

129 covalently bound to the AMP phosphate (Figure 1C). This refers to the first step of ligation

130 reaction and indicates that LIG1 stays in its initial adenylated state and cannot move forward

131 with subsequent adenyl group transfer to the $5^{\prime}-\mathrm{PO}_{4}$ on the downstream strand to activate the

132 ligase for attack by the upstream 3'-OH of nick DNA. Our LIG1/A:C mismatch structure

133 represents the first human LIG1 structure resolved in step 1. These observations suggest that

134 the $\mathrm{A}: \mathrm{C}$ base pairing imparts non-native active site conformations that further suppress the

135 chemical steps of catalysis. Overall, our LIG1/mismatch structures demonstrate that the ligase

136 is trapped as the adenylated-DNA intermediate (AMP-DNA) that favors the ligation of

137 mutagenic G:T mismatch and the active site remains in inactive conformation (AMP-K568)

138 that deters nick sealing of $\mathrm{A}: \mathrm{C}$ end.

139 Similar to the previously reported LIG1 structures (54-57), we observed that LIG1 completely

140 envelopes the DNA with DNA binding (DBD), adenylylation (AdD), and oligonucleotide

141 binding (OBD) domains encircling the nick DNA with correct or mismatched ends

142 (Supplementary Figure 2). Moreover, we observed that the structures of LIG1/A:T nick DNA

143 harbors a Watson-Crick conformation with two hydrogen bonds, while G:T and A:C 3'-

144 terminal pairs show the Wobble hydrogen bonding, which is similar to DNA

145 polymerase/mismatch structures for G:T and A:C (Figure 2 and Supplementary Figure 3).

146 LIG1 active site shows distinct DNA conformations depending on the identity of

$147 \quad$ mismatched ends

148 High-fidelity DNA synthesis requires that the polymerases display a strong preference for right

149 nucleotide insertion (22). Previously solved pol $\beta /$ mismatch structures indicated that the

150 mismatched termini adopt various distorted conformations that attempt to satisfy stacking and 
hydrogen-bonding interactions, which provides a key fidelity checkpoint (58-68). Our LIG1 structures in complex with nick DNA harboring G:T and A:C mismatched termini exhibit distinct mismatch-specific conformations. We found significant differences in the position of

1545 5'- $\mathrm{PO}_{4}$ and 3'-OH strands at a nick around the upstream and downstream DNA (Figures 2-5).

155 For the structures of LIG1 in complex with nick DNA containing G:T and A:T where the 5'-5' phosphoanhydride AMP-DNA intermediate is formed, we observed that 5'-phosphate is more close to 3'-OH strand of a nick for proper positioning and sealing a phosphodiester backbone (Figure 2C). The distances from 5'-P to 3'-OH of nick DNA with A:T and G:T are $2.1 \AA$ and $2.8 \AA$ A, respectively. In LIG1/A:C mismatch structure, we observed that 3'-OH of nick DNA rotates $50^{\circ}$ from that of nick DNA with A:T (Figure $2 \mathrm{C}$ ). The overlay of LIG1/nick structures with correctly base-paired A:T versus mismatched G:T or A:C ends also demonstrated significant differences in the conformations of 5'-strand (Figure 3A), due to clear shifts in the positions of $-1 \mathrm{G},-2 \mathrm{~T}$, and $-3 \mathrm{C}$ nucleotides relative of the upstream DNA in the structures of LIG1/G:T (Figure 3A) and A:C (Figure 3B) mismatches in comparison with LIG1/A:T nick DNA (Supplementary Figure 1).

166 Moreover, we observed the position of phenylalanine at 872 (F872) that is located upstream of 167 the nick and positioned close to the deoxyribose moiety of the nucleotide at the 5'-end shows differences in the LIG1/mismatch nick DNA structures (Figure 4A). The overlay of LIG1/nick DNA duplexes with A:T and A:C demonstrated that F872 distorts the alignment at the upstream 170 of A:T nick where $-1 \mathrm{G}$ and $+1 \mathrm{~A}$ nucleotides are in parallel between 3'- and 5'- strands (Figure

171 4B-C). In both LIG1 structures, we also found conformational differences in the active site residues $\operatorname{Arg}(\mathrm{R}) 589$ and $\operatorname{Leu}(\mathrm{L}) 544$, which are positioned close to 5'-phosphate of a nick

173 (Figure 5). The interaction interface between $\operatorname{Arg}(\mathrm{R}) 874$ and $-2 \mathrm{~T}$ nucleotide of the downstream 174 DNA shows a clear change in LIG1 structures with A:T versus A:C ends (Figure 5A). 175 Similarly, the distance between R589 and L544 side chains is shifted because of the differences 
in the position of AMP (bound to DNA at LIG1/A:T or bound to K568 active site at LIG1/A:C) as shown in the LIG1 A:T/A:C overlay structure (Figure 5B).

178 The previously solved crystal structures of LIG1 revealed $\mathrm{Mg}^{2+}$-dependent high-fidelity $179\left(\mathrm{Mg}^{\mathrm{HiFi}}\right)$ site that is coordinated by the two conserved glutamate residues at the junction 180 between Adenylation [Glu(E)346] and DNA-binding [Glu(E)592] domains of the ligase and in 181 direct interaction with DNA (54). These structures demonstrated that the mutagenesis at $\mathrm{Mg}^{\mathrm{HiFi}}$ site (E346A/E592A or EE/AA) allows LIG1 to better accommodate a damaged base (8-oxoG) in the active site. In our study, we also used EE/AA mutant for crystallizations and resolving

184 the structures of LIG1/nick with mismatched ends. Therefore, we finally compared our 185 structures with the previously solved structures of LIG1/nick harboring correct (G:C) and damaged (8-oxoG:A) ends at 3'-strand. The overlay of LIG1/G:C with our all three structures

187 (A:T, G:T, and A:C) showed no difference and the presence of $\mathrm{Mg}^{2+}$ at high-fidelity side surrounded by E346 and E592 residues (Supplementary Figure 4). The overlay of LIG1/8oxodG:A with our LIG1/G:T mismatch demonstrated the ligase structure encircling nick DNA

190 and differences in hydrogen bonding characteristic of G:T and 8-oxodG:A base pairs 191 (Supplementary Figure 5).

\section{Ligation of the nick repair intermediate with 3'-mismatch by LIG1}

193 In order to evaluate the substrate discrimination mechanism of LIG1 against the repair 194 intermediates harboring mismatched ends for which we determined the ligase/nick DNA 195 structures (Figures 1-5), we performed the ligation assays using the nick DNA substrates containing 3'-preinserted mismatches $\mathrm{dG}: \mathrm{T}$ and $\mathrm{dA}: \mathrm{C}$ in a reaction mixture including the wildtype or low-fidelity EE/AA mutant of LIG1. In our control reactions, we evaluated the ligation efficiency of nick DNA with 3'-dA:T.

199 For both LIG1 proteins, at earlier time points of ligation reaction (10-30 s), we observed an 200 efficient ligation of nick DNA substrates with 3'-dA:T (Figure 6A and 6B, lanes 2-5) and 3'- 
$\mathrm{dG}: \mathrm{T}$ (Figure $6 \mathrm{~A}$ and $6 \mathrm{~B}$, lanes 7-10) that yielded similar amount of nick sealing products

202 (Figure 6C-D). However, the end joining efficiency of LIG1 is significantly diminished in the 203 presence of $\mathrm{dA}: \mathrm{C}$ mismatch at the 3 '-end of nick DNA (Figure $6 \mathrm{~A}$ and 6B, lanes 12-15). There 204 was $\sim 90$-fold difference in the amount of ligation products between dG:T and dA:C 205 mismatches (Figure 6C). The only difference between wild-type and low-fidelity EE/AA mutant of LIG1 is the formation of DNA intermediates with 5'-adenylate (AMP). We observed more intermediate products accumulated in the presence of $3^{\prime}-\mathrm{dA}: \mathrm{C}$ and $3^{\prime}-\mathrm{dG}: \mathrm{T}$ mismatches by LIG1 EE/AA and wild-type, respectively (Supplementary Figure 6). However, even for longer time points of ligation reaction incubation (10 $\mathrm{min})$, we observed very efficient ligation

210 for the nick DNA substrates containing 3'-dA:T and 3'-dG:T and drastic decrease in nick 211 sealing efficiency of 3'-dA:C by both wild-type and EE//AA mutant of LIG1 (Supplementary

212 Figures 7 and 8 ).

213 In our previous studies, we reported that pol $\beta$ 8-oxodGTP insertion leads to ligase failure and

214 the mutation (EE/AA) at the high-fidelity site of LIG1 results in the mutagenic ligation of nick

215 repair intermediate with an inserted 8-oxodGMP (35). In the present study, we also compared 216 the DNA end-joining efficiency of LIG1 against the repair intermediates with 3'-preinserted

217 mismatch and damaged base that mimic DNA polymerase mismatch (dGTP:C) and oxidized nucleotide (8-oxodGTP:A) insertion products, respectively. For this purpose, we used the nick DNA substrates with 3'-preinserted dG:T and 8-oxodG:A in the ligation reaction as described above. In consistent with our previous studies $(32,37-40)$, we found that LIG1 EE/AA can ligate the nick DNA substrates with 3'-dG:T and 3'-8-oxodG:A efficiently (Supplementary Figure 9A, lanes 2-5 and 7-10, respectively). We did not obtain significant difference in the amount of ligation products (Supplementary Figure 9B). Similarly, wild-type LIG1 shows

224 similar end-joining efficiency for both nick DNA substrates containing mismatched and 225 damaged bases at 3'-end (Supplementary Figure 9C, lanes 2-5 and 7-10, respectively) with 
time-dependent increase in the amount of ligation products (Supplementary Figure 9D). We

227 also observed the accumulation of DNA intermediates with 5'-AMP (Supplementary Figure 228 10).

\section{Ligation of pol $\beta$ mismatch nucleotide insertion products by LIG1}

230 The discrimination of the repair intermediates by DNA ligases can impair progression of BER 231 pathway when mismatch nucleotides are inserted by pol $\beta$ (26-36). In order to further understand the effect of mismatches on the interplay between pol $\beta$ and LIG1 at the downstream steps of the BER pathway, we investigated the ligation of pol $\beta$ correct (dGTP:C) versus

234 mismatch (dGTP:T and dATP:C) nucleotide insertion products in a coupled reaction including 235 polß and LIG1 (wild-type or EE/AA mutant). For this purpose, we used one nucleotide gap 236 DNA substrates with template $\mathrm{C}$ or $\mathrm{T}$.

237 Consistent with our previous findings (32), we observed that the repair products after pol $\beta$ dGTP:T insertion were ligated efficiently by wild-type LIG1 (Figure 7A, lanes 7-10). These products are similar to the end joining products of nick repair intermediates after pol $\beta$ correct dGTP:C insertion (Figure 7A, lanes 2-5). The amount of ligation products in a coupled reaction after pol $\beta$ dGTP:T insertion was relatively lower when compared with the ligation products after pol $\beta$ dGTP:C insertion (Figure 7B). However, in the coupled reaction where we tested the ligation of pol $\beta \mathrm{dATP}$ mismatch insertion opposite $\mathrm{C}$ by wild-type LIG1 (Figure 7A, lanes 12-15), there was no ligation products (Figure 7B).

245 For low-fidelity LIG1 EE/AA mutant, we also obtained efficient end joining of pol $\beta$ dGTP:T 246 insertion product (Figure 7C, lanes 7-10). This was similar to the ligation products of pol $\beta$ correct dGTP insertion opposite $\mathrm{C}$ in the control reactions (Figure 7C, lanes 2-5). Interestingly,

248 the products of self-ligation (i.e., end joining of one nucleotide gap DNA itself) were appeared 249 simultaneously with a complete ligation of nicked insertion products (Figure 7C, compare lines 2505 and 10). Similar to the wild-type enzyme, LIG1 EE/AA mutant was not able to ligate the 
251 repair intermediate after pol $\beta$ dATP:C mismatch insertion (Figure 7C, lanes 12-15). The

252 amount of ligation products after pol $\beta$ insertions for dGTP:C was higher than those after 253 dGTP:T insertion (Figure 7D).

254 Interplay between APE1 and LIG1 during processing of the nick repair intermediates 255 with mismatched ends

256 DNA repair intermediates with a damaged or mismatched base at 3'-end could block the 257 pathway coordination and become persistent DNA strand-breaks if not repaired (14). In our 258 previous studies, we reported the role of DNA end-processing proteins Aprataxin (APTX) and 259 Flap Endonuclease 1 (FEN1) in cleaning an adenylate (AMP) block from 5'-end of the ligation 260 failure products (23-25). In order to further investigate the processing of mutagenic nick repair 261 products with an inserted mismatched bases at 3 '-end, we examined the role of APE1 as a compensatory DNA end-processing enzyme (69). For this purpose, we evaluated the $3^{\prime}-5^{\prime}$ exonuclease activity of APE1 in a reaction mixture that includes the nick DNA substrates with

264 3'-preinserted dG:T and dA:C mismatches. We did not observe a significant difference in the 265 mismatch base removal efficiency of APE1 between 3'-dG:T and 3'-dA:C mismatches (Figure 266 8A). Our results demonstrated that APE1 can remove 3'-dG and 3'-dA bases from the nick

267 DNA substrates with template base T and C, respectively (Supplementary Figure 11).

268 In line with our observations that demonstrate the end joining ability of LIG1 on the mismatch269 containing nick repair intermediates (Figure 6), we further investigated the processing of the 270 nick DNA substrates with 3'-dG:T and 3'-dA:C mismatches in coupled reactions including both 271 APE1 and LIG1 to test the efficiency of mismatch removal and ligation simultaneously. Our results demonstrated that APE1 mismatch removal products were accumulated along with the

273 ligation products for the nick DNA substrates with 3'-dG:T mismatch (Figure 8B, lanes 2-5). 
274 However, we mainly observed the products of 3'-dA mismatch removal by APE1 from the

275 nicked DNA substrate with 3'-dA:C (Figure 8B, lanes 7-10).

276 Lastly, we quantitatively monitored the real time kinetics of protein-protein interaction

277 between APE1 and LIG1 by Surface Plasmon Resonance (SPR) assay where the interacting

278 protein partner of APE1 was immobilized on CM5 biosensors onto which LIG1 protein was

279 respectively passed as an analyte. Our results, for the first time, showed protein-protein

280 interaction with the equilibrium binding constant (KD: $117 \mathrm{nM})$ between APE1 and LIG1

281 (Figure 8C). In previously published studies, the physical interactions for APE1 were reported

282 for the core BER proteins such as DNA glycosylase MYH, pol $\beta$, and XRCC1 $(19,20)$.

283 Thermodynamics and domain mapping studies also showed that pol $\beta$ interacts with the N-

284 terminal noncatalytic part of LIG1 $(70,71)$. Overall, it seems that the interplay within the multi-

285 protein BER process when bound to a repair intermediate with an incompatible end could affect

286 the repair efficiency at the downstream steps.

287 Discussion

288 The BER is a critical process for preventing the mutagenic and lethal consequences of complex types of lesions (15). The fidelity of BER requires tightly coordinated series of enzymatic steps, which is critical to prevent the release and accumulation of toxic and mutagenic single-strand break intermediates that contribute to genome instability (16-18). Although structural and biochemical studies have provided extensive evidence for sequential substrate-product

293 shuttling for faithful BER coordination at earlier steps of the repair pathway, the molecular coordination at the downstream steps involving pol $\beta$ gap filling and final DNA ligation by ligase I or III $\alpha$ remains largely unknown.

296 Kinetic, structural, and computational studies have demonstrated that the pol $\beta$ active site

297 undergoes a conformational change to form the precatalytic closed ternary complex in the

298 presence of a Watson-Crick base pairing, known as an induced-fit mechanism, exhibits diverse 
mismatch-induced conformational distortions that is dependent on the architecture of the

300 mismatched template primer (58-68). The largest distortion has been reported for A:C

301 mismatch where O3' $^{\prime}$ of the primer terminus sugar is positioned away from the active site by

302 precluding direct template base interactions, which results in a loss of one hydrogen bond, and

303 therefore, effectively deters further DNA synthesis $(64,65)$. Pol $\beta$ structures also revealed that

304 the polymerase active site with an inserted dGMP opposite T escapes mismatch discrimination

305 through ionization of the wobble base pair and exhibits a Watson-Crick-like conformation in a

306 closed state (58-68). Despite of these pol $\beta$ binary and ternary complex structures with a variety

307 of mismatches, how downstream proteins, particularly DNA ligase, engage with the mismatch-

308 containing repair intermediates is still lacking. In our present study, we determined at atomic

309 resolution the features of the DNA substrate and LIG1 interaction that dictate accurate versus

310 mutagenic outcomes to define the critical elements of accurate BER at final steps of the repair

311 pathway.

312 In this work, we used structural and biochemical approaches to elucidate the mechanisms by

313 which LIG1 discriminates against mutagenic 3'-mismatches that could be formed during prior

314 pol $\beta$ mismatch nucleotide insertion step of the BER pathway. Our study reveals that LIG1

315 discriminates 3 ' termini depending on the architecture of mismatched ends at during steps 1

316 (ligase adenylation) and step 2 (AMP transfer to DNA) of the ligation reaction. The structure

317 of LIG1 bound to nick DNA duplexes with A:T and G:T showed that the ligase can ligate G:T

318 mismatch with two hydrogen bonds and a base-pair size that is nearly indistinguishable from

319 that of a Watson-Crick A:T base pair. Both structures refer to LIG1 bound to AMP-DNA nick

320 as step 2 product of ligase reaction. We also showed efficient nick sealing of DNA substrates

321 with 3'-preinserted $\mathrm{dA}: \mathrm{T}$ and $\mathrm{dG}: \mathrm{T}$ to a significant degree with high efficiency in ligation

322 reactions in vitro. Importantly, our structures revealed that the LIG1 active site is quite rigid

323 and ligation differences between nick DNA substrates with G:T and A:C mismatches likely 
324 result from altered DNA conformations. Crystal structure of LIG1/nick DNA with A:C

325 mismatch demonstrated that the mismatched termini distorts the conformations of $3^{\prime}$ - and 5'-

326 strands of a nick. Overall, our results demonstrate that the extent to which G:T versus A:C

327 mismatch discrimination by LIG1 counteracts the polymerase-promoted mutagenesis products

328 distinctly at the downstream steps of BER pathway.

329 All mammalian and bacterial ATP-dependent DNA ligases contain a highly conserved the 330 catalytic core consisting of the oligonucleotide binding domain (OBD) and the adenylation

331 (AdD) or nucleotidyl transferase (NTase) domain (3-5). Despite of this C-terminal core 332 architecture, they display different fidelity profiles depending on the type (human ligase I, III $\alpha$, 333 or IV) and source of DNA ligase (54-57,73-95). Metal ions play important roles in steps 1 and

3343 of the ligation reaction (1-13). The catalytic $\mathrm{Mg}^{2+}$ ion deprotonates the lysine nucleophile to 335 activate it to attack on the ATP $\alpha$-phosphate and stabilize the pentavalent transition state formed 336 during step 1, while the metal ion activates 3'-OH nucleophilic attack on the 5'-phosphate and 337 form the pentavalent transition during final nick sealing step 3 (73-95). We crystallized LIG1 338 EE/AA in complex with matched A:T and mismatched G:T and A:C nick DNA under similar 339 conditions in the absence of metal ion. Most structures of ATP-dependent DNA ligases have 340 no divalent cation in the refined model and the mechanism of step 1 during which LIG1 341 engages with catalytic $\mathrm{Mg}^{2+}$ and ATP remains unclear at atomic resolution. Previously solved 342 crystal structures of DNA ligase/ATP and ligase/ATP/ $\mathrm{Mg}^{2+}$ complexes for ATP-dependent 343 ligases from other sources such as Chlorella virus DNA ligase, T4 DNA ligase, Mycobacterium tuberculosis LigD, and Pyrococcus furiosus DNA ligase in a noncovalent complex with AMP enlighten the requirement of metal ion for the ligase adenylation (83-94). The present study represents a human LIG1 bound to ATP (LIG1-AMP) in step 1 of ligation reaction while 347 engaging with nick DNA harboring A:C mismatched termini at 3'-strand. 
348 Based on our structural and biochemical results, according to our model (Supplementary

349 Scheme 3), we hypothesized that the LIG1-nick repair intermediate with a poor mismatch

350 (A:C) versus a good match (A:T) architecture could serve as a structural fidelity checkpoint at

351 which the efficiency of repair pathway coordination is mediated at the final ligation step.

352 Furthermore, the pol $\beta$ mismatched versus matched-substrate/product complex could also 353 determine the fate of substrate-product channeling that can deter or favor final nick sealing step

354 in the BER pathway. This phenomenon could provide an opportunity for 3'-proofreading by

355 APE1. It has been also reported in the structure studies that the nick with a mismatched base

356 exhibits distinct features where 3 '-end slides into the APE1 active site and a mismatched end

357 is stabilized by protein contacts (96). It is also likely that other $3^{\prime}-5^{\prime}$ exonucleases can also

358 provide a proofreading function at the downstream steps of BER pathway for 3'-end cleaning

359 (97). Importantly, our study uncovered a mutagenic event where the architecture of LIG1/nick

360 duplex with G:T mismatch in the active site forms a premutagenic structural intermediate. In

361 our previous study, we reported that DNA polymerase (pol) $\mu$ dGTP mismatch insertion

362 opposite $\mathrm{T}$ during gap filling repair synthesis in the nonhomologous end joining (NHEJ)

363 pathway is effectively coupled with ligation by DNA ligase IV, resulting in the formation of

364 promutagenic NHEJ intermediate (30). Recently, the crystal structures of pol $\mu$

365 misincorporating dGTP on gap DNA substrate containing template $\mathrm{T}$ revealed its highly

366 mutagenic base pairing role at the $3^{\prime}$ end of the gap during NHEJ (98). Further

367 structure/function studies with both BER DNA ligases (ligase I and III $\alpha$ ) are required for all

368 other possible non-canonical base pairings at 3'-end of a nick to comprehensively understand

369 the ligase strategies against the mutagenic repair intermediates that could be formed due to

370 aberrant BER function of pol $\beta$ such as cancer-associated variants with slower or lack of gap

371 filling activity and reduced fidelity (37-46).

372 Methods 
374 Oligodeoxyribonucleotides with and without a 6-carboxyfluorescein (FAM) label were obtained from Integrated DNA Technologies (IDT). DNA substrates were prepared as

376 described previously (23-36). The nick DNA substrates containing 3'-preinserted correct 377 (dA:T), mismatch (dG:T and dA:C), or damaged (8-oxodG:A) ends with a FAM label at 3'-end were used for DNA ligation assays in a reaction mixture including LIG1 (wild-type or EE/AA mutant) alone (Supplementary Table 1). The one nucleotide gap DNA substrates containing FAM labels at both 3'-and 5'-ends were used for the coupled assays to observe the ligation of pol $\beta$ correct or mismatch nucleotide insertion products by LIG1 (wild-type or EE/AA mutant) in the same reaction mixture including both pol $\beta$ and LIG1 (Supplementary Table 2). The nick DNA substrates containing 3'-preinserted correct (dA:T) or mismatch (dG:T and dA:C) with a FAM label at 5'-end were used for APE1 exonuclease assays in a reaction mixture including APE1 alone (Supplementary Table 3). The nick mismatch containing DNA substrates with FAM labels at both 3'- and 5'-ends were used in the coupled assays to observe APE1 mismatch removal and ligation in the same reaction mixture including both APE1 and LIG1

388 (Supplementary Table 4). For LIG1 X-ray crystallography studies, the nick DNA substrates containing correct $\mathrm{A}: \mathrm{T}$ and mismatch $\mathrm{G}: \mathrm{T}$ and $\mathrm{A}: \mathrm{C}$ ends were prepared by annealing upstream, downstream, and template primers (Supplementary Table 5).

\section{Protein purifications}

392 Human his-tag recombinant full-length (1-918) wild-type DNA ligase I (LIG1) and C-terminal 393 ( $\triangle 261)$ E346A/E592A (EE/AA) mutant were purified as described previously (23-36). Briefly, 394 the proteins were overexpressed in Rosetta (DE3) pLysS E. coli cells (Millipore Sigma) and 395 grown in Terrific Broth (TB) media with kanamycin $\left(50 \mu \mathrm{gml}^{-1}\right)$ and chloramphenicol $396\left(34 \mu \mathrm{gml}^{-1}\right)$ at $37{ }^{\circ} \mathrm{C}$. Once the OD was reached to 1.0 , the cells were induced with $0.5 \mathrm{mM}$ 397 isopropyl $\beta$-D-thiogalactoside (IPTG) and the overexpression was continued for overnight at 
$28^{\circ} \mathrm{C}$. After the centrifugation, the cell was lysed in the lysis buffer containing $50 \mathrm{mM}$ Tris$\mathrm{HCl}$ (pH 7.0), $500 \mathrm{mM} \mathrm{NaCl}, 20 \mathrm{mM}$ imidazole, 10\% glycerol, $1 \mathrm{mM}$ PMSF, an EDTA-free protease inhibitor cocktail tablet by sonication at $4{ }^{\circ} \mathrm{C}$. The lysate was pelleted at $16,000 \mathrm{x} \mathrm{rpm}$

401 for $1 \mathrm{~h}$ at $4{ }^{\circ} \mathrm{C}$. The cell lysis solution was filter clarified and then loaded onto a HisTrap HP 402 column (GE Health Sciences) that was previously equilibrated with the binding buffer 403 including $50 \mathrm{mM}$ Tris- $\mathrm{HCl}$ (pH 7.0), $500 \mathrm{mM} \mathrm{NaCl}, 20 \mathrm{mM}$ imidazole, $10 \%$ glycerol. The 404 column was washed with the binding buffer and then followed by washing buffer containing 405 $50 \mathrm{mM}$ Tris- $\mathrm{HCl}(\mathrm{pH} 7.0), 500 \mathrm{mM} \mathrm{NaCl}, 35 \mathrm{mM}$ imidazole, $10 \%$ glycerol. The protein was 406 finally eluted with an increasing imidazole gradient $0-500 \mathrm{mM}$ at $4{ }^{\circ} \mathrm{C}$. The collected fractions 407 were then subsequently loaded onto HiTrap Heparin (GE Health Sciences) column that was 408 equilibrated with binding buffer containing $50 \mathrm{mM}$ Tris- $\mathrm{HCl}(\mathrm{pH}$ 7.0), $50 \mathrm{mM} \mathrm{NaCl}, 0.2 \mathrm{mM}$ EDTA, and $10 \%$ glycerol, and protein is eluted with a linear gradient of $\mathrm{NaCl}$ up to $1 \mathrm{M}$. The LIG1 protein was further purified by Resource Q and finally by Superdex 200 10/300 (GE 411 Health Sciences) columns in the buffer containing $20 \mathrm{mM}$ Tris- $\mathrm{HCl}(\mathrm{pH} 7.0), 200 \mathrm{mM} \mathrm{NaCl}$, 412 and $5 \%$ glycerol.

413 Human wild-type AP-Endonuclease 1 (APE1) with his-tag (pET-24b) was overexpressed and 414 purified as previously described (23-36). Briefly, the protein was overexpressed in 415 BL21(DE3)E.coli cells (Invitrogen) in Lysogeny Broth (LB) media at $37^{\circ} \mathrm{C}$ for $8 \mathrm{~h}$, induced 416 with $0.5 \mathrm{mM}$ IPTG and the overexpression was continued for overnight at $28{ }^{\circ} \mathrm{C}$. After the 417 cells were harvested, lysed at $4{ }^{\circ} \mathrm{C}$, and then clarified as described above. The supernatant was 418 loaded onto a HisTrap HP column (GE Health Sciences) and purified with an increasing 419 imidazole gradient $(0-300 \mathrm{mM})$ elution at $4{ }^{\circ} \mathrm{C}$. The collected fractions were then subsequently 420 loaded onto a HiTrap Heparin column (GE Health Sciences) with a linear gradient of NaCl up 421 to $1 \mathrm{M}$. The recombinant APE1 were then further purified by Superdex 200 increase 10/300 
422 chromatography (GE Healthcare) in the buffer containing $20 \mathrm{mM}$ Tris- $\mathrm{HCl}(\mathrm{pH} 7.0), 200 \mathrm{mM}$

$423 \mathrm{NaCl}$, and $1 \mathrm{mM}$ DTT.

424 Human wild-type pol $\beta$ with GST-tag (pGEX-6p-1) were overexpressed and purified as 425 previously described (23-36). Briefly, the protein was overexpressed in One Shot 426 BL21(DE3)pLysS E.coli cells (Invitrogen) in LB media at $37^{\circ} \mathrm{C}$ for $8 \mathrm{~h}$, induced with $0.5 \mathrm{mM}$

427 IPTG, and the overexpression was continued for overnight at $28^{\circ} \mathrm{C}$. The cells were then grown overnight at $16{ }^{\circ} \mathrm{C}$. After cell lysis at $4{ }^{\circ} \mathrm{C}$ by sonication in the lysis buffer containing $1 \mathrm{X}$ PBS (pH 7.3), $200 \mathrm{mM} \mathrm{NaCl}$, and $1 \mathrm{mM}$ DTT, and cOmplete Protease Inhibitor Cocktail (Roche), the lysate was pelleted at $16,000 \mathrm{x}$ rpm for $1 \mathrm{~h}$ and then clarified by centrifugation and filtration.

431 The supernatant was loaded onto a GSTrap HP column (GE Health Sciences) and purified with 432 the elution buffer containing $50 \mathrm{mM}$ Tris- $\mathrm{HCl}(\mathrm{pH}$ 8.0) and $10 \mathrm{mM}$ reduced glutathione. In order to cleave a GST-tag, the recombinant protein was incubated with PreScission Protease (GE Health Sciences) for $16 \mathrm{~h}$ at $4{ }^{\circ} \mathrm{C}$ in the buffer containing $1 \mathrm{X}$ PBS (pH 7.3), $200 \mathrm{mM} \mathrm{NaCl}$, and $1 \mathrm{mM}$ DTT. After the cleavage, the pol $\beta$ protein was subsequently passed through a GSTrap HP column, and the protein without GST-tag were then further purified by loading onto Superdex 200 gel filtration column (GE Health Sciences) in the buffer containing $50 \mathrm{mM}$ Tris- $\mathrm{HCl}(\mathrm{pH} 7.5)$ and $400 \mathrm{mM} \mathrm{NaCl}$. All proteins purified in this study were dialyzed against storage buffer including $25 \mathrm{mM}$ Tris- $\mathrm{HCl}(\mathrm{pH} 7.0), 200 \mathrm{mM} \mathrm{NaCl}$, concentrated, frozen in

440 liquid nitrogen, and stored at $-80{ }^{\circ} \mathrm{C}$. Protein quality was evaluated onto $10 \%$ SDS-PAGE, and 441 the protein concentration was measured using absorbance at $280 \mathrm{~nm}$.

\section{Crystallization and structure determination}

443 LIG1 C-terminal $(\Delta 261)$ EE/AA mutant was used for crystals production. All the LIG1-DNA 444 complex crystals were grown at $20{ }^{\circ} \mathrm{C}$ using the hanging drop method. LIG1 (at 26 mgml $^{-1}$ 445 LIG1)/DNA complex solution was prepared in $20 \mathrm{mM}$ Tris- $\mathrm{HCl}(\mathrm{pH} 7.0), 200 \mathrm{mM} \mathrm{NaCl}, 1$ $446 \mathrm{mM}$ DTT, $0.1 \mathrm{mM}$ EDTA and $1 \mathrm{mM}$ ATP at 1.5:1 DNA:protein molar ratio of nick DNA and 
then mixed with $1 \mu \mathrm{l}$ reservoir solution containing $100 \mathrm{mM}$ MES (pH 6.6), $100 \mathrm{mM}$ lithium acetate, and 20\% (w/v) polyethylene glycol PEG3350. All crystals grew in 1-2 days and they were washed in the reservoir solution with $20 \%$ glycerol and flash cooled in liquid nitrogen for data collection. The crystals were maintained at $100 \mathrm{~K}$ during X-ray diffraction data collection using the beamline 7B2 at Cornell High Energy Synchrotron Source (CHESS). The diffraction images were indexed and integrated using HKL2000. All structures were solved by the molecular replacement method using PHASER using PDB entry 6P0D as a search model (54). Iterative rounds of model building in COOT and refinement with PHENIX or REFMAC5 were used to produce the final models (99-103). All structural images were drawn using PyMOL (The PyMOL Molecular Graphics System, V0.99, Schrödinger, LLC). Detailed crystallographic statistics are provided in Table 1.

\section{DNA ligation assays}

459 The ligation assays using the nick DNA substrates containing 3'-preinserted correct dA:T, 460 mismatched dG:T or dA:C, and damaged 8-oxodG:A ends were performed (Supplementary 461 Scheme 1A) as described previously (23-36). Briefly, the ligation assays were performed in a 462 mixture containing $50 \mathrm{mM}$ Tris- $\mathrm{HCl}(\mathrm{pH} 7.5), 100 \mathrm{mM} \mathrm{KCl}, 10 \mathrm{mM} \mathrm{MgCl}, 1 \mathrm{mM} \mathrm{ATP}, 1$ $\mathrm{mM}$ DTT, $100 \mu \mathrm{gml}^{-1} \mathrm{BSA}, 10 \%$ glycerol, and $500 \mathrm{nM}$ DNA substrate in a final volume of 10

$464 \mu 1$. The reactions were initiated by the addition of 100 nM LIG1 (wild-type or EE/AA mutant), 465 incubated at $37^{\circ} \mathrm{C}$, and stopped at the time points indicated in the figure legends. The reaction 466 products were then quenched with an equal amount of gel loading buffer containing 95\% 467 formamide, $20 \mathrm{mM}$ ethylenediaminetetraacetic acid, $0.02 \%$ bromophenol blue and $0.02 \%$ 468 xylene cyanol. After incubation at $95{ }^{\circ} \mathrm{C}$ for $3 \mathrm{~min}$, the reaction products were separated by 469 electrophoresis on an $18 \%$ denaturing polyacrylamide gel. The gels were scanned with a 470 Typhoon PhosphorImager (Amersham Typhoon RGB), and the data were analyzed using 471 ImageQuant software. 
473 The one nucleotide gap DNA substrates with template A or C were used to test the ligation of 474 pol $\beta$ nucleotide insertion (correct or mismatch) products in the reaction mixture including pol $\beta$ and LIG1 (Supplementary Scheme 1B) as described previously (23-36). Briefly, the coupled assays were performed in a mixture containing $50 \mathrm{mM}$ Tris- $\mathrm{HCl}(\mathrm{pH} 7.5), 100 \mathrm{mM} \mathrm{KCl}, 10$ $\mathrm{mM} \mathrm{MgCl} 2,1 \mathrm{mM}$ ATP, $1 \mathrm{mM}$ DTT, $100 \mu \mathrm{gml}^{-1} \mathrm{BSA}, 10 \%$ glycerol, $100 \mu \mathrm{M}$ dNTP, and 500 nM DNA substrate in a final volume of $10 \mu 1$. The reactions were initiated by the addition of pre-incubated enzyme mixture of pol $\beta /$ LIG1 $(100 \mathrm{nM})$ and incubated at $37^{\circ} \mathrm{C}$ for the time points as indicated in the figure legends. The reaction products were then mixed with an equal amount of gel loading buffer, separated by electrophoresis on an $18 \%$ denaturing polyacrylamide gel, and analyzed as described above.

\section{BER assays to measure APE1 exonuclease activity and LIG1 ligation}

The nick DNA substrates including 3'-preinserted mismatches $\mathrm{dG}: \mathrm{T}$ and $\mathrm{dA}: \mathrm{C}$ were used to examine APE1 proofreading role for removing a mismatched base by its $3{ }^{\prime}-5^{\prime}$ exonuclease activity (Supplementary Scheme 2A). Briefly, APE1 activity assays were performed in a mixture containing $50 \mathrm{mM}$ HEPES (pH 7.4), $100 \mathrm{mM} \mathrm{KCl,} 3 \mathrm{mM} \mathrm{MgCl}_{2}, 0.1 \mathrm{mgml}^{-1} \mathrm{BSA}$, and $500 \mathrm{nM}$ DNA substrate in a final volume of $10 \mu \mathrm{l}$. The reactions were initiated by the addition of $50 \mathrm{nM}$ APE1, incubated at $37{ }^{\circ} \mathrm{C}$ for the time points as indicated in the figure legends, quenched by mixing with $100 \mathrm{mM}$ EDTA, and then mixed with an equal amount of gel loading buffer. The nick DNA substrates including 3'-preinserted mismatches dG:T and $\mathrm{dA}: \mathrm{C}$ were used for repair assays to test APE1 exonuclease and DNA ligation activities in the same reaction mixture (Supplementary Scheme 2B). Briefly, the repair assays were performed in a mixture containing $50 \mathrm{mM}$ HEPES (pH 7.4), $100 \mathrm{mM} \mathrm{KCl,} 5 \mathrm{mM} \mathrm{MgCl} 2,1 \mathrm{mM}$ ATP, 0.1 $\mathrm{mgml}^{-1} \mathrm{BSA}$, and $500 \mathrm{nM}$ DNA substrate in a final volume of $10 \mu \mathrm{l}$. The reactions were initiated by the addition of pre-incubated enzyme mixture including APE1/LIG1 (100 nM), 
incubated at $37^{\circ} \mathrm{C}$ for the time points as indicated in the figure legends. The reaction products were quenched by mixing with $100 \mathrm{mM}$ EDTA and then mixed with an equal amount of gel

499 loading buffer. The reaction products were separated by electrophoresis on an $18 \%$ denaturing

500 polyacrylamide gel and analyzed as described above.

\section{APE1 and LIG1 protein-protein interaction assay}

502 The protein-protein interaction between APE1 and LIG1 was measured by Surface Plasmon 503 Resonance (SPR) in real time using Biacore X-100 (GE Healthcare) as described previously 504 (36). Briefly, one flow cell of the CM5 sensor chip was activated at $25^{\circ} \mathrm{C}$ with a 1:1 mixture 505 of $0.2 \mathrm{M} \mathrm{EDC}$ and $0.05 \mathrm{M}$ NHS in water, and then APE1 protein was injected over the flow 506 cell in $10 \mathrm{mM}$ sodium acetate at $\mathrm{pH} 5.0$ at a flow rate of $10 \mu \mathrm{l} / \mathrm{min}$. The binding sites were 507 blocked using $1 \mathrm{M}$ ethanolamine. LIG1 (at the concentration range of 0-1.6 $\mu \mathrm{M}$ ) was then 508 injected for $3 \mathrm{~min}$ at a flow rate of $30 \mu \mathrm{l} / \mathrm{min}$ in the binding buffer $(20 \mathrm{mM}$ HEPES pH 7.4, 150 $\mathrm{mM} \mathrm{NaCl}, 3 \mathrm{mM}$ EDTA and $0.005 \%$ (v/v) Surfactant P20). After a dissociation phase for 3-4

$510 \min , 0.2 \%$ SDS was injected for $30 \mathrm{sec}$ to regenerate the chip surface. Non-specific binding to

511 a blank flow cell was subtracted to obtain corrected sensorgrams. All data were analyzed using 512 BIAevaluation software version 2.0.1 and fitted to a 1:1 (Langmuir) binding model to obtain 513 equilibrium constant $(\mathrm{K} D)$.

\section{Data availability}

515 Atomic coordinates and structure factors for the reported crystal structures have been deposited 516 in the RCSB Protein Data Bank under accession numbers 7SUM, 7SXE, 7SX5. All relevant 517 data are available from the authors upon reasonable request.

\section{$518 \quad$ References}

519 1. Timson, D. J., Singleton, M. R. \& Wigley, D. B. DNA ligases in the repair and 520 replication of DNA. Mutat. Res. 460, 301-318 (2000). 
2. Shuman, S. DNA ligases: progress and prospects. J. Biol. Chem. 284, 17365-17369 (2009).

3. Tomkinson, A. E., Vijayakumar, S., Pascal, J. M. \& Ellenberger, T. DNA ligases: structure, reaction mechanism, and function. Chem. Rev. 106, 687-699 (2006).

4. Doherty, A. J. \& Suh, S. W. Structural and mechanistic conservation in DNA ligases. Nucleic Acids Res. 28, 4051-4058 (2000).

5. Ellenberger, T. \& Tomkinson, A. E. Eukaryotic DNA ligases: Structural and functional insights. Annu. Rev. Biochem. 77, 313-338 (2008).

6. Cherepanov, A.V.\& Vries, S. Dynamic mechanism of nick recognition by DNA ligase. Eur. J. Biochem. 269, 5993-5999 (2002).

7. Dickson, K. S., Burns, C. M. \& Richardson, J. P. Determination of the free-energy change for repair of a DNA phosphodiester bond. J. Biol. Chem. 275, 15828-15831 (2000).

8. Weiss, B., Thompson, A. \& Richardson, C. C. Ezymatic breakage and joining of deoxyribonucleic acid. VII. Properties of the enzyme-adenylate intermediate in the polynucleotide ligase reaction. J. Biol. Chem. 243, 4556-4563 (1968).

9. Singleton, M. R., Hakansson, K., Timson, D. J. \& Wigley, D. B. Structure of the adenylation domain of an NAD ${ }^{+}$-dependent DNA ligase. Structure 7, 35-42 (1999).

10. Tomkinson, A. E., Totty, N. F., Ginsburg, M. \& Lindahl, T. Location of the active-site the successive reaction by human DNA ligases I and II. J. Biol. Chem. 267, 8117-8122 (1992). 

DNA ligase I reveals magnesium-dependent changes in the rate-limiting step that compromise ligation efficiency. J. Biol. Chem. 286, 23054-23062 (2011).

13. Cherepanov, A. V. \& Vries, S. Kinetics and thermodynamics of nick sealing by T4 DNA ligase. Eur. J. Biochem. 270, 4315-4325 (2003).

14. Caglayan, M. Interplay between DNA polymerases and DNA ligases: Influence on substrate channeling and the fidelity of DNA ligation. J. Mol. Biol. 431, 2068-2081 (2019).

15. Beard, W. A. et al. Eukaryotic base excision repair: New approaches shine light on mechanism. Ann. Rev. Biochem. 88, 137-162 (2019).

16. Prasad, R. et al. A review of recent experiments on step-to-step "hand-off" of the DNA intermediates in mammalian base excision repair pathways. Mol. Biol. 45, 586-600 (2011).

17. Prasad, R., Shock, D. D., Beard, W. A. \& Wilson, S. H. Substrate channeling in mammalian base excision repair pathways: passing the baton. J. Biol. Chem. 285, 40479-40488 (2010).

18. Wilson, S. H. \& Kunkel, T. A. Passing the baton in base excision repair. Nat. Struct. Biol. 7, 176-178 (2000).

19. Moor, N. A. et al. Quantitative characterization of protein-protein complexes involved Biochemistry 83, 411-422 (2018). (2015). 
22. Beard, W. A. et al. Efficiency of correct nucleotide insertion governs DNA polymerase fidelity. J. Biol. Chem. 277, 47393-47398 (2002).

23. Caglayan, M. et al. Role of polymerase $\beta$ in complementing aprataxin deficiency during abasic-site base excision repair. Nat. Struct. Mol. Biol. 21, 497-499 (2014).

24. Caglayan, M. et al. Complementation of aprataxin deficiency by base excision repair enzymes. Nucleic Acids Res. 43, 2271-2281 (2015).

25. Caglayan, M. et al. Complementation of aprataxin deficiency by base excision repair enzymes in mitochondrial extracts. Nucleic Acids Res. 45, 10079-10088 (2017).

26. Caglayan, M. et al. Oxidized nucleotide insertion by pol $\beta$ confounds ligation during base excision repair. Nat. Commun. 8, 14045 (2017).

27. Caglayan, M. \& Wilson, S. H. Role of DNA polymerase $\beta$ oxidized nucleotide insertion in DNA ligation failure. J. Radiat. Res. 58, 603-607 (2017).

28. Horton, J. K. et al. XRCC1 phosphorylation affects aprataxin recruitment and DNA deadenylation activity. DNA Repair 64, 26-33 (2018).

29. Prasad, R. et al. DNA polymerase $\beta$ : The missing link of the base excision repair

30. Caglayan, M. \& Wilson, S. H. Pol $\mu$ dGTP mismatch insertion opposite T coupled with ligation reveals a promutagenic DNA intermediate during double strand break repair. Nat. Comm. 9, 4213 (2018).

31. Caglayan M. Pol $\mu$ ribonucleotide insertion opposite 8-oxodG facilitates the ligation of premutagenic DNA repair intermediate. Sci. Rep. 10, 940 (2020).

32. Caglayan, M. The ligation of pol $\beta$ mismatch insertion products governs the formation of promutagenic base excision DNA repair intermediates. Nucleic Acids Res. 48, 37083721 (2020). 
33. Caglayan, M. Pol $\beta$ gap filling, DNA ligation and substrate-product channeling during base excision repair opposite oxidized 5-methylcytosine modifications. DNA Repair 95,102945 (2020).

34. Tang, Q., Kamble, P. \& Caglayan, M. DNA ligase I variants fail in the ligation of mutagenic repair intermediates with mismatches and oxidative DNA damage. Mutagenesis 35, 391-404 (2020).

35. Kamble, P., Hall, K., Chandak, M., Tang, Q. \& Caglayan, M. DNA ligase I fidelity the mutagenic ligation of pol $\beta$ oxidized and mismatch nucleotide insertion products in base excision repair. J. Biol. Chem. 296,100427 (2021).

36. Tang, Q. \& Caglayan, M. The scaffold protein XRCC1 stabilizes the formation of polß/gap DNA and ligase III $\alpha /$ nick DNA complexes in base excision repair. J. Biol. Chem. 297, 101025 (2021).

37. Donigan, K. A. et al. Human polymerase $\beta$ is mutated in high percentage of colorectal tumors. J. Biol. Chem. 287, 23830-23839 (2012).

38. Starcevic, D. et al. Is there a link between DNA polymerase $\beta$ and cancer? Cell Cyle $\mathbf{3}$, 998-1001 (2004).

39. Alnajjar, K. S. et al. A change in the rate-determining step of polymerization by the K289M DNA polymerase $\beta$ cancer-associated variant. Biochemistry 56, 2096-2105 (2017).

40. Shah, A. M. et al. Variants of DNA polymerase $\beta$ extend mispaired DNA due to increased affinity for nucleotide substrate. Biochemistry 42, 10709-10717 (2003). mouse cells results in cellular transformation. Proc. Natl. Acad. Sci. U S A 102, 1435014355 (2005). 
618 42. Donigan, K. A. et al. The human gastric cancer-associated DNA polymerase beta variant $\mathrm{D} 160 \mathrm{~N}$ is a mutator that indices cellular transformation. DNA Repair 12, 381390 (2012).

43. Lang, T. et al. The E295K DNA polymerase $\beta$ gastric cancer-associated variant interferes with base excision repair and induces cellular transformation. Mol. Cell Biol. 27, 5587-5596 (2007).

44. Donigan, K. A. et al. DNA polymerase $\beta$ variant Ile260Met generates global gene expression changes related to cellular transformation. Mutagenesis 27, 683-691 (2012).

45. Yamtich, J. et al. A germline polymorphism of DNA polymerase $\beta$ induces genomic instability and cellular transformation. PLOS Gen. 8, e10003052 (2012).

46. Nemec, A. A. et al. The S229L colon tumor-associated variant of DNA polymerase $\beta$ induces cellular transformation as a result of decreased polymerization efficiency. $J$. Biol. Chem. 289, 13708-13716 (2014).

47. Burgers, P. M. J. \& Kunkel, T. A. Eukaryotic DNA replication fork. Annu. Rev. Biochem. 86, 417-438 (2017).

48. Modrich, P. DNA mismatch correction. Annu. Rev. Biochem. 56, 435-466 (1987).

49. Topal, M. D. \& Fresco, J. R. Complementary base pairing and the origin of substitution mutations. Nature 263, 285-289 (1976).

50. Bebenek, K., Pedersen, L. C. \& Kunkel, T. A. Replication infidelity via a mismatch with Watson-Crick geometry. Proc. Natl. Acad Sci. U S A 108, 1862-1867 (2011). hypothesis of spontaneous mutagenesis. Proc. Natl. Acad Sci. US A 108, 17644-17648 (2011). 
52. Harris, V. H. et al. The effect of tautomeric constant on the specificity of nucleotide incorporation during DNA replication: support for the rare tautomer hypothesis of substitution mutagenesis. J. Mol. Biol. 326, 1389-1401 (2003).

53. Kimsey, I. J. et al. Visualizing transient Watson-Crick-like mispairs in DNA and RNA duplexes. Nature 519, 315-320 (2015).

54. Tumbale, P. P. et al. Two-tiered enforcement of high-fidelity DNA ligation. Nat. Commun. 10, 5431 (2019).

55. Pascal, J. M. et al. Human DNA ligase I completely encircles and partially unwinds nicked DNA. Nature 432, 473-478 (2004).

56. Williams, J. S. et al. High-fidelity DNA ligation enforces accurate Okazaki fragment maturation during DNA replication. Nat. Commun. 12, 482 (2021).

57. Jurkiw, T. J. et al. LIG1 syndrome mutations remodel a cooperative network of ligand binding interactions to compromise ligation efficiency. Nucleic Acids Res. 49, 1619$1630(2021)$.

58. Beard, W. A. \& Wilson, S. H. Structural insights into the origins of DNA polymerase fidelity. Structure 11, 489-496 (2003).

59. Batra, V. K., Beard, W. A., Shock, D. D., Pedersen, L. C. \& Wilson, S. H. Nucleotide12141-12144 (1996). switch. J. Biol. Chem., 283, 26297-26301 (2008). 
62. Sawaya, M. R., Prasad, R., Wilson, S. H., Kraut, J. \& Pelletier, H. Crystal structures of human DNA polymerase beta complexed with gapped and nicked DNA: evidence for an induced fit mechanism. Biochemistry 36, 11205-11215 (1997).

63. Krahn, J. M., Beard, W. A. \& Wilson, S. H. Structural insights into DNA polymerase $\beta$ deterrents for misincorporation support an induced-fit mechanism for fidelity. Structure 12, 1823-1832 (2004).

64. Batra, V. K., Beard, W. A., Pedersen, L. C. \& Wilson, S. H. Structures of DNA polymerase mispaired DNA termini transitioning to pre-catalytic complexes support an induced-fit fidelity mechanism. Structure 24, 1863-1875 (2016).

65. Batra, V. K., Beard, W. A., Shock, D. D., Pedersen, L. C. \& Wilson, S. H. Structures of DNA polymerase $\beta$ with active-site mismatches suggest a transient abasic site intermediate during misincorporation. Mol. Cell. 30, 315-324 (2008).

66. Beard, W. A., Shock, D. D., Yang, X. P., DeLauder, S. F. \& Wilson, S. H. Loss of DNA polymerase $\beta$ stacking interactions with templating purines, but not pyrimidines, alters catalytic efficiency and fidelity. J. Biol. Chem. 277, 8235-8242 (2002).

67. Koag, M. C., Nam, K. \& Lee, S. The spontaneous replication error and the mismatch discrimination mechanisms of human DNA polymerase $\beta$. Nucleic Acids Res. 42 , 11233-11245 (2014).

68. Ahn, J., Kraynov, V. S., Zhong, X., Werneburg, B. G. \& Tsai, M. D. DNA polymerase $\beta$ : effects of gapped DNA substrates on dNTP specificity, fidelity, processivity and conformational changes. Biochem. J. 331, 79-87 (1998).

69. Whitaker, A. M. \& Freudenthal, B. D. APE1: A skilled nucleic acid surgeon. DNA Repair 71, 93-100 (2018). 
70. Prasad, R. et al. Specific interaction of DNA polymerase $\beta$ and DNA ligase I in a multiprotein base excision repair complex from bovine testis. J. Biol. Chem., 271, 16000-16007 (1996).

71. Dimitriadis, E. K. et al. Thermodynamics of human DNA ligase I trimerization and association with DNA polymerase $\beta$. J. Biol. Chem., 273, 20540-20550 (1998).

72. Cotner-Gohara, E. et al. Human DNA ligase III recognizes DNA ends by dynamic switching between two DNA-bound states. Biochemistry 49, 6165-6176 (2010).

73. Taylor, R. M. et al. The DNA ligase III zinc finger stimulates binding to DNA secondary structure and promotes end joining. Nucleic Acids Res. 28, 3558-3563 (2000).

74. Cuneo, M. J. et al. The structural basis for partitioning of the XRCC1/DNA ligase IIIa BRCT-mediated dimer complexes. Nucleic Acids Res. 39, 7816-7827 (2011).

75. Hammel, M. et al. An atypical BRCT-BRCT interaction with the XRCC1 scaffold protein compacts human DNA ligase III $\alpha$ within a flexible DNA repair complex. Nucleic Acids Res. 49, 306-321 (2021).

76. Conlin, M. P. et al. DNA ligase IV guides end-processing choice during nonhomologous end joining. Cell Rep. 20, 2810-2819 (2017).

77. Ochi, T., Gu, X. \& Blundell, T. L. Structure of the catalytic region of DNA ligase IV in complex with an Artemis fragment sheds light on double-strand break repair. Structure 21, 672-679 (2013).

78. Ochi, T. et al. Structural insights into the role of domain flexibility in human DNA ligase IV. Structure 20, 1212-1222 (2012).

79. Kaminski, A. et al. Structures of DNA-bound human ligase IV catalytic core reveal insights into substrate binding and catalysis. Nat. Commun. 9, 2642 (2018). 

cerevisiae: Physical and biochemical characterization of the CDC9 gene product. Biochemistry 31, 11762-11771(1992).

81. Shi, K. et al. T4 DNA ligase structure reveals a prototypical ATP-dependent ligase with a unique mode of sliding clamp interaction. Nucleic Acids Res. 46, 10474-10488 (2018).

82. Bogenhagen, D. F. \& Pinz, K. G. The action of DNA ligase at abasic sites in DNA. $J$. Biol. Chem. 273, 7888-7893 (1998).

83. Nishida, H., Kiyonari, S., Ishino, Y. \& Morikawa, K. The closed structure of an archaeal DNA ligase from Pyrococcus furiosus. J. Mol. Biol. 360, 956-967 (2006).

84. Chen, Y. et al. Structure of the error-prone DNA ligase of African swine fever virus identifies critical active site residues. Nat. Commun. 10, 387 (2019).

85. Unciuleac, M., Goldgur, Y. \& Shuman, S. Structures of ATP-bound DNA ligase D in

86. Shuman, S. \& Lima, C. D. The polynucleotide ligase and RNA capping enzyme superfamily of covalent nucleotidyltransferases. Curr. Opin. Struct. Biol. 14, 757-764 (2004).

87. Pascal, J. M. DNA and RNA ligases: structural variations ands hared mechanisms. Curr. Opin. Struct. Biol. 18, 96-105 (2008).

88. Subramanya, H. S., Doherty, A. J., Ashford, S. R. \& Wigley, D. B. Crystal structure of an ATP-dependent DNA ligase from bacteriophage T7. Cell 85, 607- 615 (1996).

89. Odell, M., Sriskanda, V., Shuman, S. \& Nikolov, D. Crystalstructure of eukaryotic DNA ligase-adenylate illuminates the mechanism of nick sensing and strand joining. Mol. Cell 6, 1183-1193 (2000). 
90. Nair, P. A., Nandakumar, J., Smith, P., Odell, M., Lima, C. D. \& Shuman, S. Structural basis for nick recognition by a minimal pluripotent DNA ligase. Nat. Struct. Mol. Biol. 14, $770-778$ (2007).

91. Gong, C., Martins, A., Bongiorno, P., Glickman, M. \& Shuman, S. Biochemical and genetic analysis of the four DNA ligases of mycobacteria. J. Biol. Chem. 279, 2059420606 (2004).

92. Gong, C., Bongiorno, P., Martins, A., Stephanou, N. C., Zhu, H., Shuman, S. \& Glickman, M. S. Mechanism of non-homologous end joining in mycobacteria: a lowfidelity repair system driven by Ku, ligase D and ligase C. Nat. Struct. Mol. Biol. 12, 304-312 (2005).

93. Akey, D., Martins, A., Aniukwu, J., Glickman, M. S., Shuman, S. \& Berger, J. M. Crystal structure and nonhomologous end joining function of the ligase component of Mycobacterium DNA ligase D. J. Biol. Chem. 281, 13412-13423 (2006).

94. Williamson, A., Rothweiler, U. \& Leiros, H. K. Enzyme-adenylate structure of a bacterial ATP-dependent DNA ligase with a minimized DNA-binding surface. Acta Crystallogr. D 70, 3043-3056 (2014).

95. Williamson, A., Grgic, M. \& Leiros, H. S. DNA binding with a minimal scaffold: structure-function analysis of Lig E DNA ligases. Nucleic Acids Res. 46, 8616- 8629 (2018).

96. Whitaker, A. M., Flynn, T. S. \&. Freudenthal, B. D. Molecular snapshots of APE1 proofreading mismatches and removing DNA damage. Nat. Comm. 9, 399 (2019).

97. Andres, S. N. et al. Recognition and repair of chemically heterogeneous structures at DNA ends. Environ. Mol. Mutagen. 56, 1-21 (2015)

98. Guo, M. et al. Mechanism of genome instability mediated by human DNA polymerase mu misincorporation. Nat. Commun. 12, 3759 (2021). 
99. Otwinowski, Z. \& Minor, W. Processing of X-ray diffraction data collected in oscillation mode. Methods Enzymol. 276, 307-326 (1997).

100. McCoy, A. J. et al. Phaser crystallographic software. J. Appl. Crystallogr. 40, 658-674 (2007).

101. Emsley, P. et al. Features and development of Coot. Acta Crystallogr. D. Biol. Crystallogr. 66, 486-501 (2010).

102. Adams, P. D. et al. PHENIX: a comprehensive Python-based system for macromolecular structure solution. Acta Crystallogr. D. Biol. Crystallogr. 66, 213-221 (2010).

103. Murshudov, G. N. et al. REFMAC5 for the refinement of macromolecular crystal structures. Acta Crystallogr. D. Biol. Crystallogr. 67, 355-367 (2011).

\section{Funding}

This work was supported by the National Institutes of Health/National Institute of Environmental Health Sciences Grant 4R00ES026191 and the University of Florida Thomas H. Maren Junior Investigator Fund P0158597.

\section{Acknowledgements}

This work is based upon research conducted at the Center for High Energy X-ray Sciences (CHEXS), which is supported by the National Science Foundation under award DMR1829070, and the Macromolecular Diffraction at CHESS (MacCHESS) facility, which is supported by award 1-P30-GM124166-01A1 from the National Institute of General Medical Sciences, National Institutes of Health, and by New York State's Empire State Development Corporation (NYSTAR). The authors thank Jacob E. Combs (McKenna Lab, University of Florida) for his assistance with crystal shipment and data collection.

\section{Author contributions}


Conceptualization M.Ç., methodology and investigation M.Ç., T.Q.; writing-original draft,

787 M.Ç., T.Q.; writing-reviewing and editing, M.Ç., T.Q., R.M.; funding acquisition M.Ç.

788

789

790

791

792

793

794

795

796
A

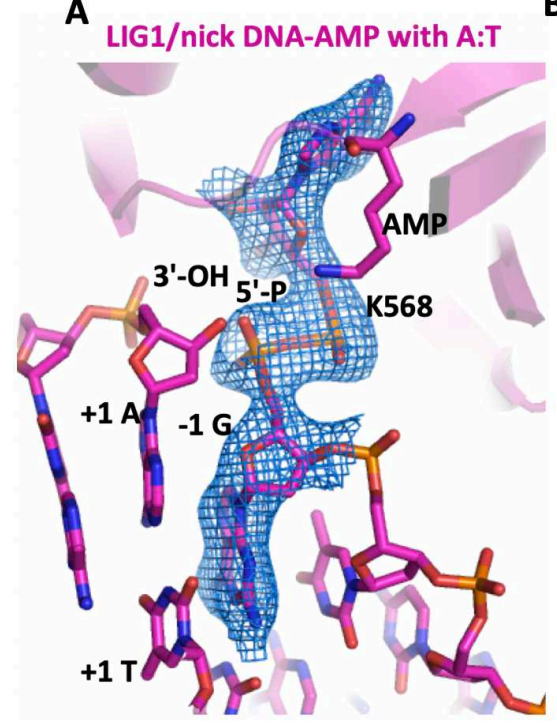

B LIG1/nick DNA-AMP with G:T

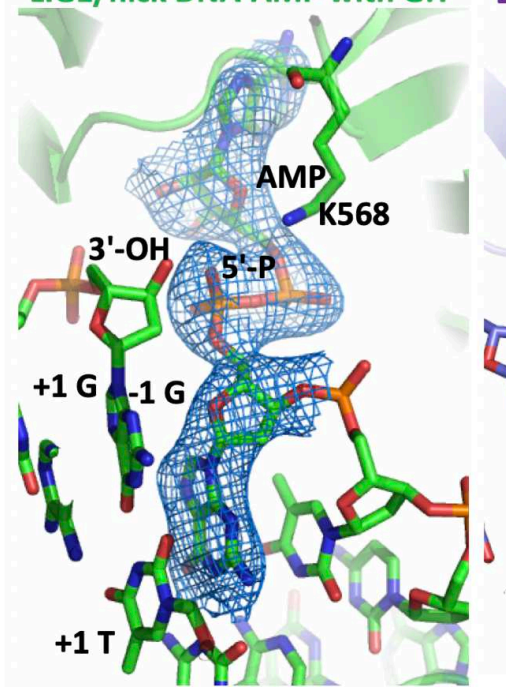

C LIG1-AMP/nick DNA with A:C

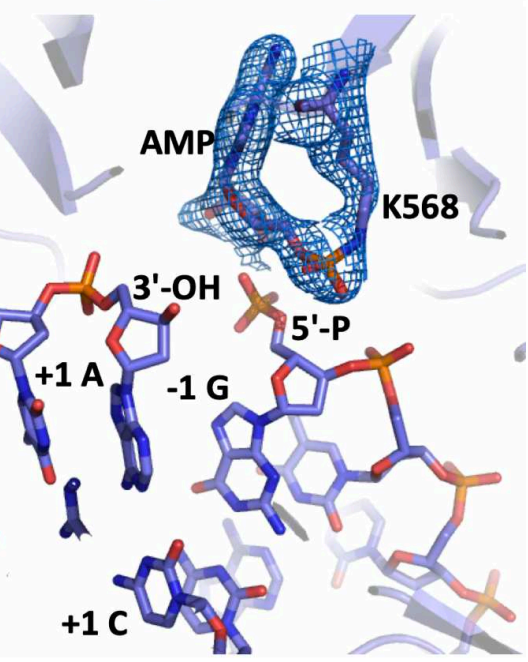

Figure 1. Structures of LIG1 bound to nick DNA duplexes with G:T and A:C mismatches.

X-ray crystal structures of LIG1/nick DNA duplexes with A:T (A), G:T (B), and A:C (C) at 3'-strand. LIG1/A:T (magenta) and G:T (green) structures with AMP-DNA complex weighted 2Fo-Fc electron density contoured at $1 \sigma$ are displayed for the adenylated 5'-phosphate of the nick (DNA-AMP). The structure of LIG1/A:C (blue) with the ligase-AMP complex weighted 2Fo-Fc electron density contoured at $1 \sigma$ is displayed for adenylated LIG1 (LIG1-AMP) at K568 active site residue. DNA and LIG1 are shown as sticks and cartoon, respectively, and AMP is depicted in blue. 
A

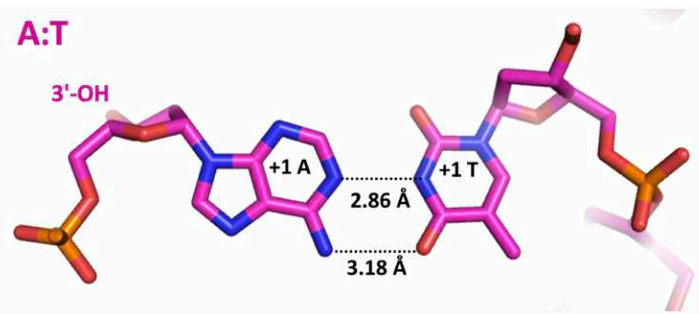

6.T

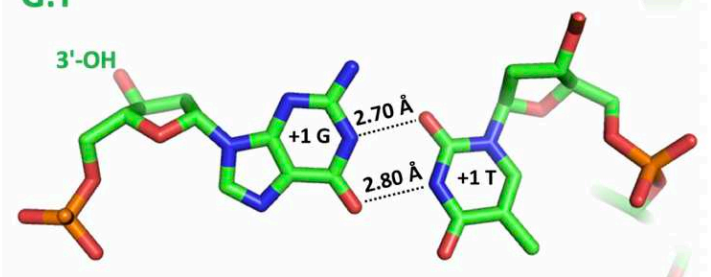

A:C

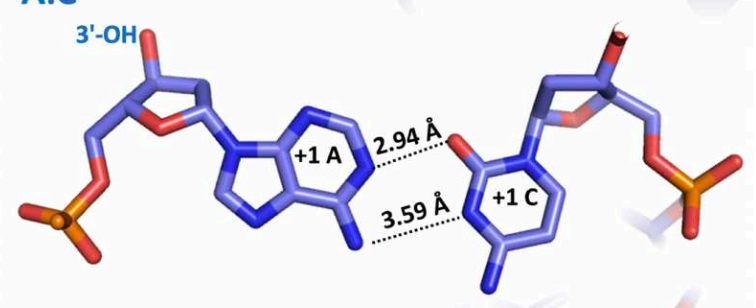

B

A/G/A

$\mathrm{T} / \mathrm{T} / \mathrm{C}$

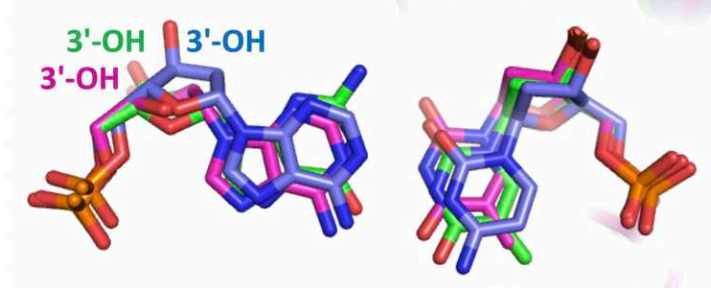

C

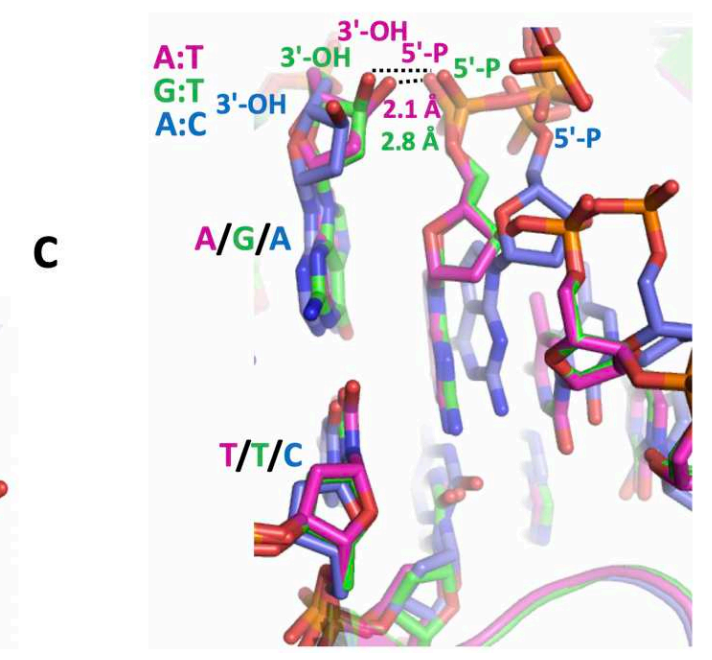

797

798 Figure 2. LIG1/nick duplexes with mismatched ends exhibit different DNA

799 conformations. (A) Hydrogen-bonding patterns of A:T, G:T, and A:C base-pairs. (B,C)

800 Overlay of LIG1 X-ray structures bound to the nick DNA duplexes with A:T (magenta), G:T

801 (green) and A:C (blue). The mismatched 3'-OH strand bound in the LIG1/nick DNA complexes

802 (B) is depicted to show differences in the distances between 5'-P and 3'-OH ends of a nick (C). 
A

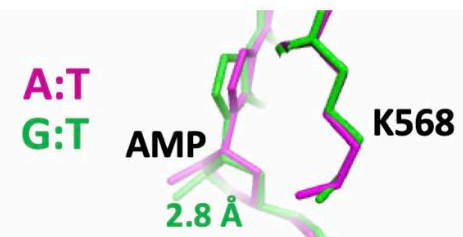

803

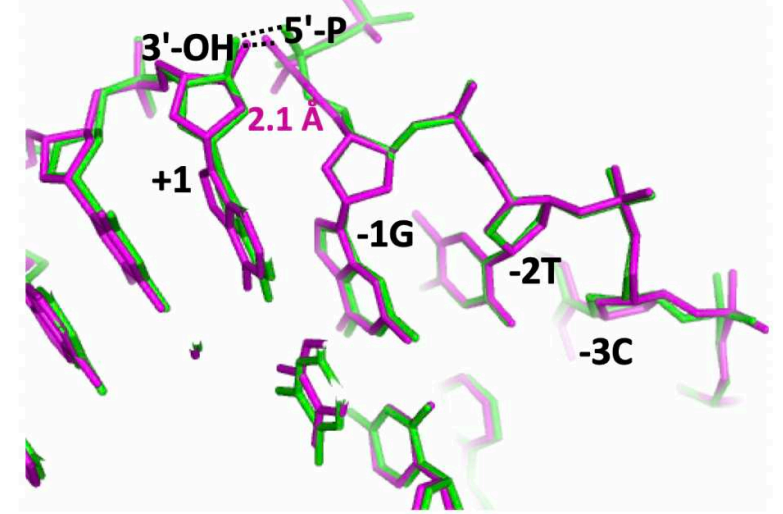

B

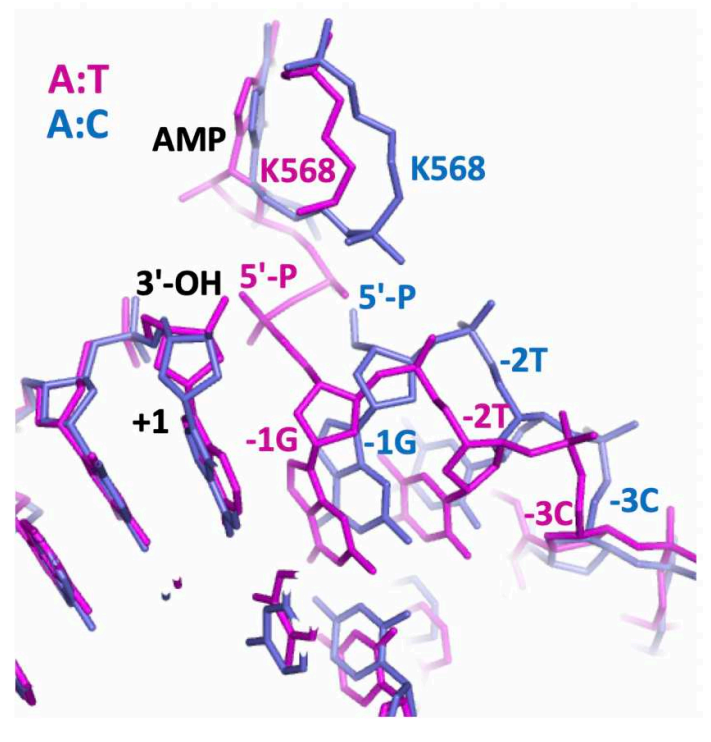

804 Figure 3. LIG1 active site bound to nick DNA duplexes with mismatched ends. Overlay of

805 LIG1/nick DNA duplexes for A:T/G:T (magenta/green) and A:T/A:C (magenta/blue)

806 structures in panels A and B, respectively. The superimposition of LIG1/nick duplexes show

807 the differences in the position of adenylate (AMP) bound to nick DNA (G:T mismatch) or 808 K568 active site (A:C mismatch) of LIG1.

A

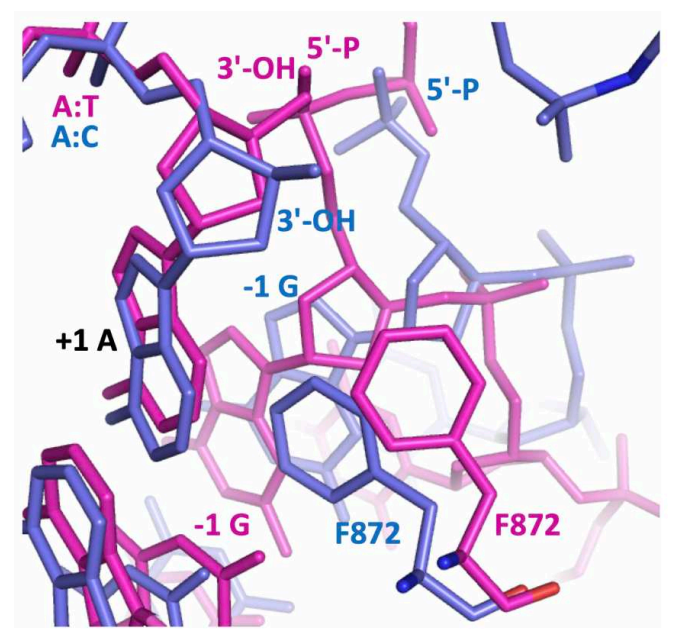

B

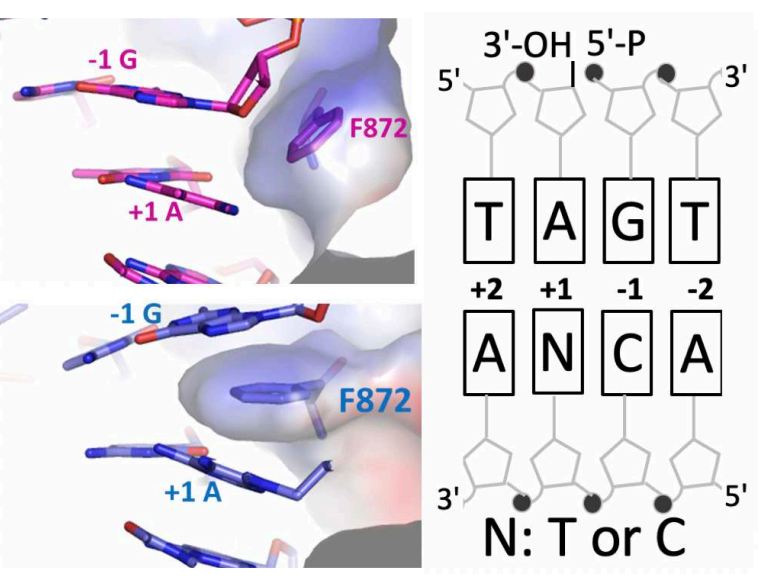

Figure 4. Structures of LIG1 F872 in complex with nick DNA complexes with mismatched

811 ends. (A) Overlay of LIG1 X-ray structures bound to the nick DNA duplexes with A:T

812 (magenta) and A:C (blue) show the conformational change at F872 (stick). (B) Surface 
813 representations of LIG1 X-ray structures depict protein-DNA contacts at F872 with +1A and -

$8141 \mathrm{G}$ bases of nick DNA.

A

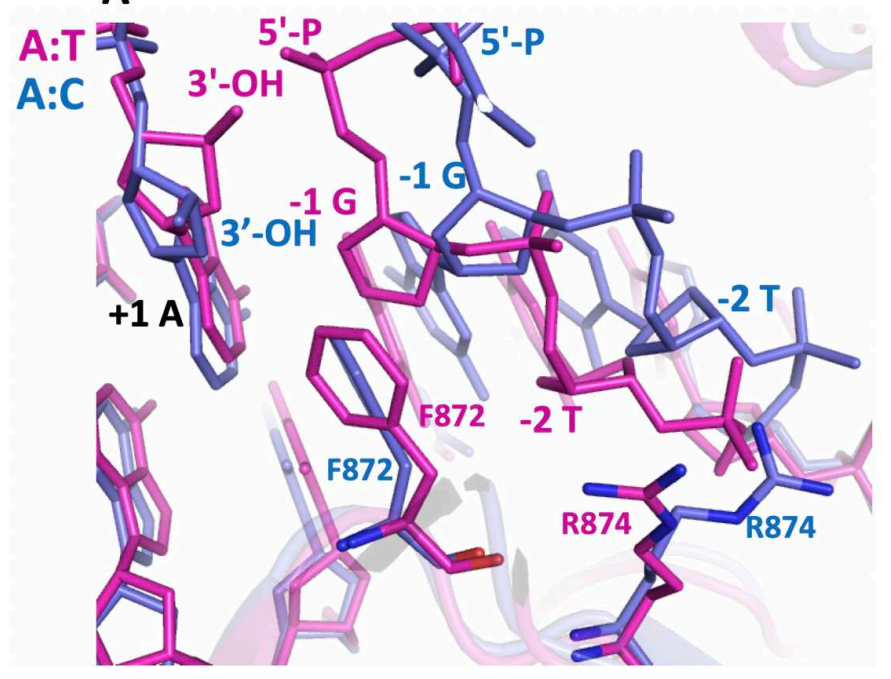

B

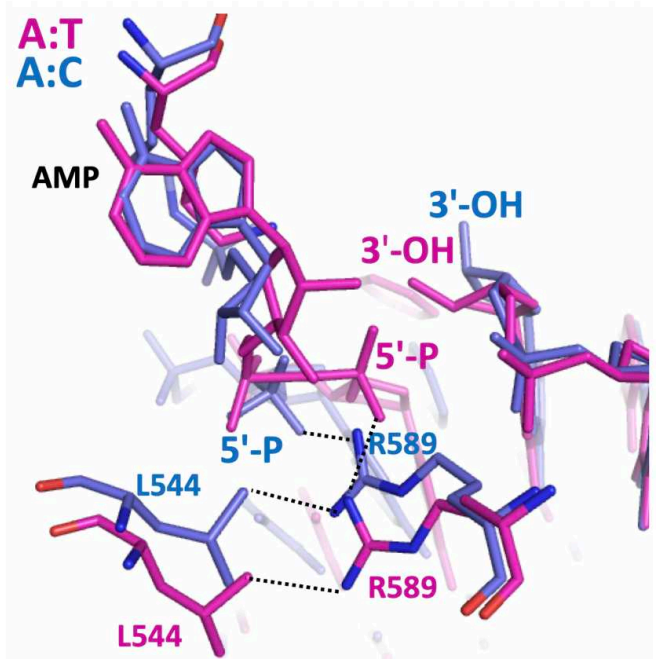

816 Figure 5. LIG1 active site residues in complex with nick DNA complexes with mismatched

817 ends. Overlay of LIG1 structures bound to the nick DNA duplexes with A:T (magenta) and

818 A:C (blue) show the positions of F872, R874 (A) and R589, L544 (B). F872 and the

819 neighboring R874 make direct DNA contacts with nucleotides -1G and -2T, respectively. R589

820 is positioned close to 5'-PO 4 end and makes a contact with $\mathrm{L} 544$ side chain. 

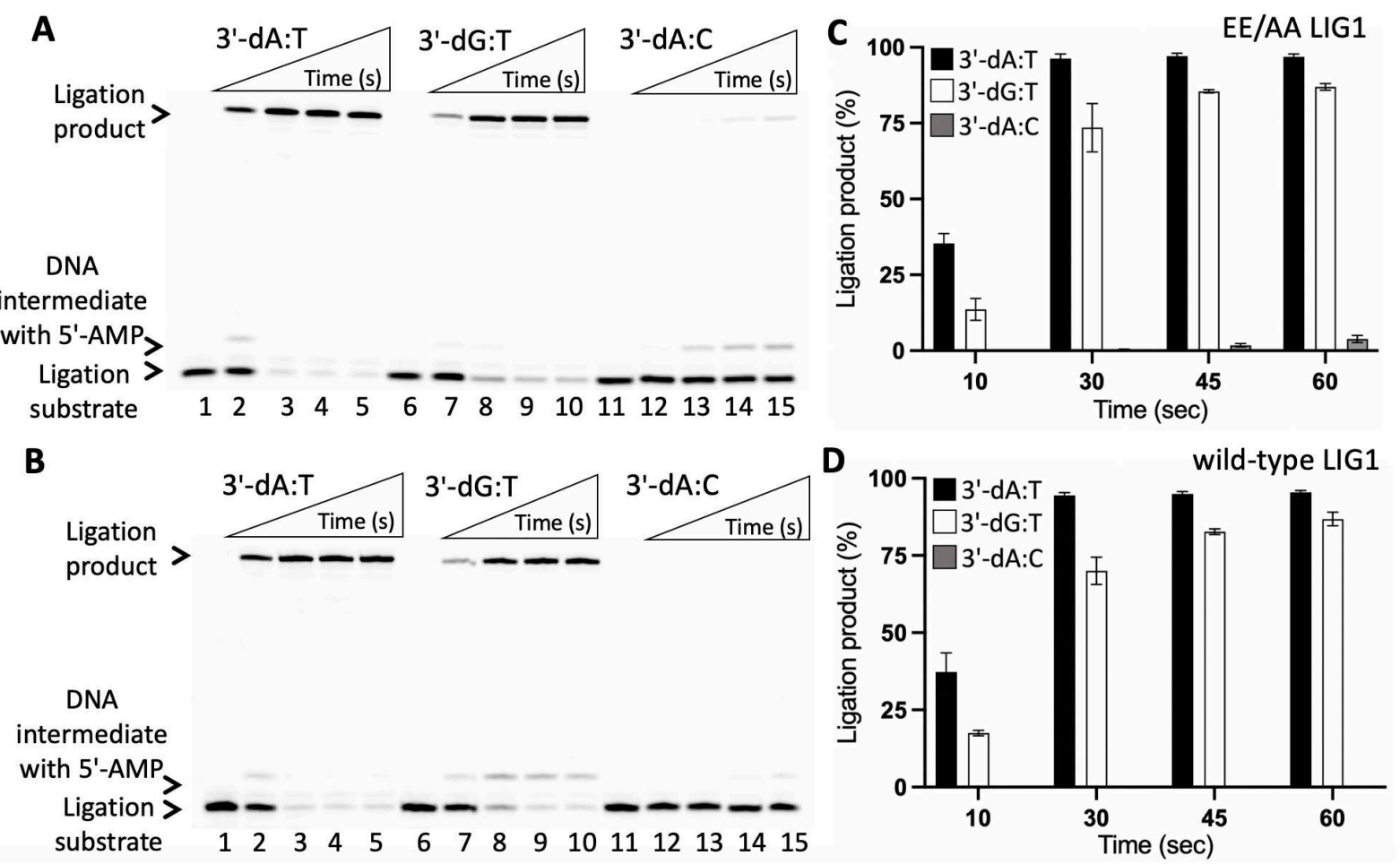

Figure 6. Ligation of nick repair intermediate with G:T and A:C mismatches by LIG1.

823 (A,B) Lanes 1, 6, and 11 are the negative enzyme controls of the nick DNA substrates with 3'-

824 preinserted dA:T, dG:T, and dA:C, respectively. Lanes 2-5, 7-10, and 12-15 are the reaction

825 products for nick sealing of DNA substrates with 3'-preinserted dA:T, dG:T, and dA:C,

826 respectively, by EE/AA (A) and wild-type (B) of LIG1, and correspond to time points of 10,

82730,45 , and $60 \mathrm{sec}$ (C,D) The graphs show time-dependent changes in the amount of ligation

828 products. The data represent the average of three independent experiments \pm SD. 

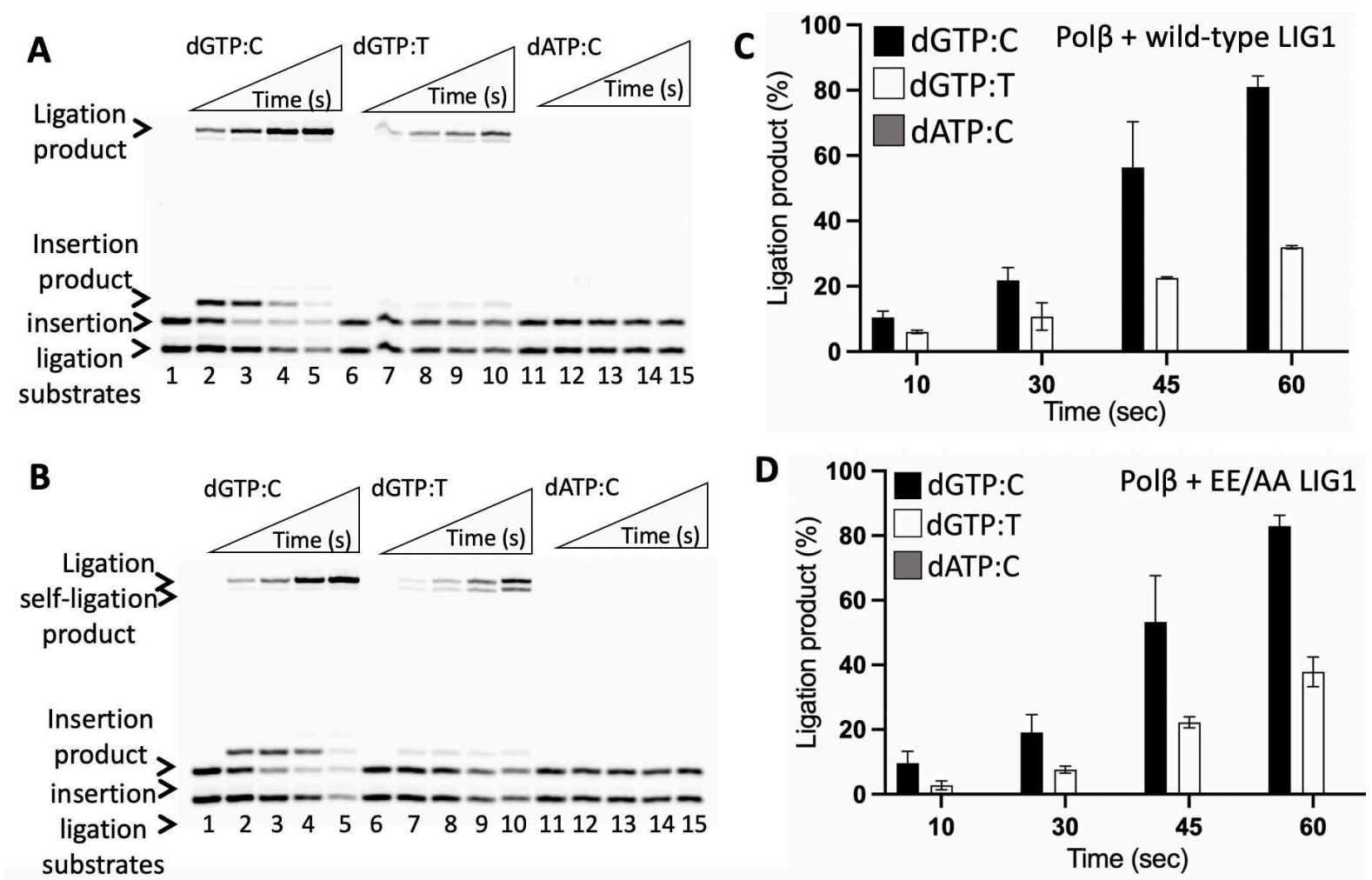

830 Figure 7. Ligation of polß mismatch nucleotide insertion products by LIG1. (A,B) Lanes

8311,6 , and 11 are the negative enzyme controls of the one nucleotide gap DNA substrate with

832 template $\mathrm{C}, \mathrm{T}$, and $\mathrm{C}$, respectively. Lanes $2-5,7-10$, and 12-15 are the reaction products for the

833 ligation of pol $\beta$ dGTP:C, dGTP:T, dATP:C insertions by wild-type (A) and EE/AA (B) of

834 LIG1, respectively, and correspond to time points of 10, 30, 45, and $60 \mathrm{sec}$. (C,D) The graphs

835 show time-dependent changes in the amount of ligation products. The data represent the 836 average of three independent experiments \pm SD. 

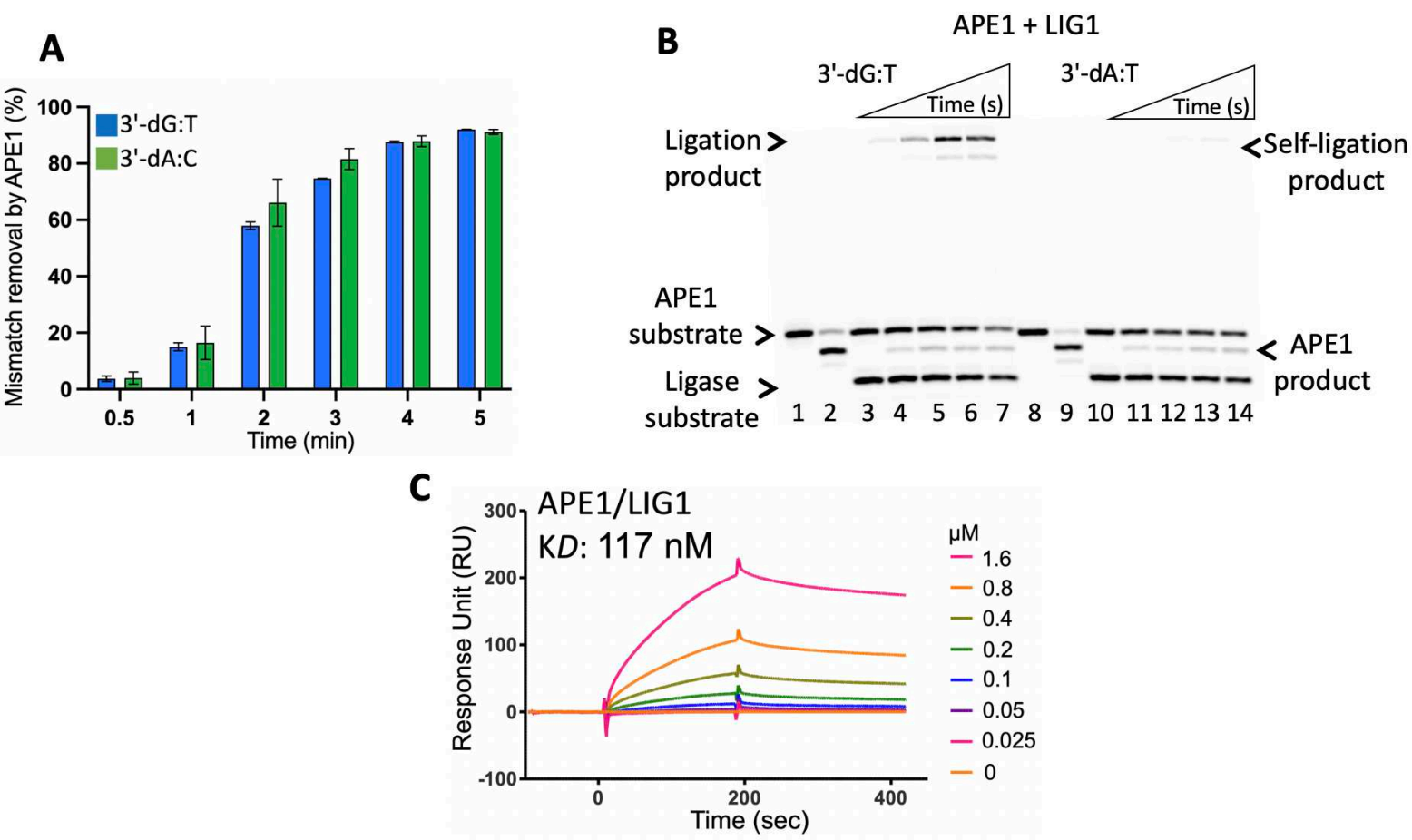

838 Figure 8. APE1 and LIG1 interplay on the repair intermediate with G:T and A:C

839 mismatches. (A) APE1 activity on the removal of a mismatched bases from the nick repair

840 intermediates with 3'-preinserted dG:T and dA:C. The graph shows time-dependent changes in

841 the amount of APE1 excision products. The data represent the average of three independent experiments \pm SD. (B) APE1 mismatch removal coupled to ligation by LIG1. Lanes 1 and 8 are the negative enzyme controls and lanes 2 and 9 are APE1 mismatch removal products for

844 the nick DNA substrates with 3'-preinserted dG:T and dA:C, respectively. Lanes 3-7 and 10-

84514 are the reaction products for APE1 mismatch removal and nick sealing of DNA substrates

846 with 3'-preinserted dG:T and dA:C, respectively, and correspond to time points of 10, 30, 45,

847 60, and $120 \mathrm{sec}$ (C) Real-time protein-protein interaction analysis between APE1 and LIG1. 
853 A:T, G:T and A:C ends at 3'-strand.

854

\begin{tabular}{|c|c|c|c|}
\hline & $\mathrm{LIG} 1^{\mathrm{EE} / \mathrm{AA}} \mathrm{A}: \mathrm{T}$ & LIG1 $1^{\mathrm{EE} / \mathrm{AA}} \mathrm{G}: \mathrm{T}$ & $\mathrm{LIGI}^{\mathrm{EE} / \mathrm{AA}} \mathrm{A}: \mathrm{C}$ \\
\hline PDB entry ID & 7SUM & 7SXE & $7 \mathrm{SX} 5$ \\
\hline \multicolumn{4}{|l|}{ Data collection } \\
\hline Space group & $\mathrm{P} 2{ }_{1}{ }_{1} 2_{1}$ & $\mathrm{P} 2{ }_{1} 2_{1} 2_{1}$ & $\mathrm{P} 2{ }_{1} 2{ }_{1}{ }_{1}$ \\
\hline \multicolumn{4}{|l|}{ Cell dimensions } \\
\hline$a, b, c(\AA)$ & $\begin{array}{lll}65.255 & 116.59 & 124.16\end{array}$ & $64.254 \quad 116.00 \quad 125.63$ & $\begin{array}{llll}63.755 & 116.41 & 126.01\end{array}$ \\
\hline $\mathrm{a}, \mathrm{b}, \mathrm{g}\left(^{\circ}\right)$ & 90 & 90 & 90 \\
\hline Resolution $(\AA)$ & $20-2.90(2.95-2.90)$ & $20-3.0(3.05-3.0)$ & $20-2.8(2.85-2.8)$ \\
\hline$R_{\mathrm{sym}}$ & $0.126(0.868)$ & $0.173(1.425)$ & $0.188(0.759)$ \\
\hline$I / \sigma(I)$ & $21.2(2.8)$ & $17.7(1.5)$ & $12.5(1.7)$ \\
\hline$C C_{1 / 2}$ & $0.995(0.827)$ & $0.988(0.733)$ & $0.947(0.707)$ \\
\hline$C C^{*}$ & $0.999(0.951)$ & $0.997(0.920)$ & $0.986(0.910)$ \\
\hline Completeness $(\%)$ & $99.9(99.7)$ & $99.8(99.5)$ & $99.0(98.1)$ \\
\hline Redundancy & $12.2(11.9)$ & $11.4(11.2)$ & $6.3(6.1)$ \\
\hline \multicolumn{4}{|l|}{ Refinement } \\
\hline Resolution $(\AA)$ & $20-2.90$ & $20-3.0$ & $20-2.8$ \\
\hline No. reflections & 21183 & 19238 & 22098 \\
\hline$R_{\text {work }} / R_{\text {free }}$ & $0.182 / 0.227$ & $0.204 / 0.245$ & $0.175 / 0.212$ \\
\hline \multicolumn{4}{|l|}{ Non-H atoms: } \\
\hline Protein/DNA & 5752 & 5491 & 5728 \\
\hline AMP & 22 & 22 & 23 \\
\hline Solvent & 141 & 38 & 182 \\
\hline \multicolumn{4}{|c|}{ Average B-factors $\left(\AA^{2}\right)$ : } \\
\hline Protein/DNA & 54.28 & 85.58 & 38.91 \\
\hline AMP & 40.62 & 87.39 & 32.12 \\
\hline Solvent & 42.28 & 44.52 & 29.70 \\
\hline \multicolumn{4}{|l|}{ R.M.S.D } \\
\hline Bond lengths ( $\AA)$ & 0.013 & 0.013 & 0.012 \\
\hline Bond angles $\left(^{\circ}\right)$ & 1.41 & 1.42 & 1.36 \\
\hline
\end{tabular}




\section{Supplementary Files}

This is a list of supplementary files associated with this preprint. Click to download.

- SupplementaryData.pdf 